\title{
The periodic transient kinetics method for investi- gation of kinetic process dynamics under realistic conditions: Methanation as an example
}

\author{
Dominik Meyer, Jens Friedland, Jannik Schumacher, Robert Güttel* \\ Institute of Chemical Engineering, Ulm University, \\ Albert-Einstein-Allee 11, 89081 Ulm, Germany \\ ${ }^{*}$ Corresponding author \\ E-mail address: robert.guettel@uni-ulm.de
}

\begin{abstract}
Due to rising interest for the integration of chemical energy storage into the electrical power grid, the unsteady-state operation of chemical reactors is gaining more and more attention with emphasis on heterogeneously catalyzed reactions. The transient response of those reactions is influenced by effects on different length scales, ranging from the active surface via the individual porous catalyst particle up to the full-scale reactor. The challenge, however, is to characterize unsteady-state effects under realistic operation conditions and to assign them to distinct transport processes. Therefore, the periodic transient kinetics (PTK) method is introduced, which allows for the separation of kinetic process dynamics at different length scales experimentally under realistic operation conditions. The methodology also provides the capability for statistical analysis of the experimental results and therefore improved reliability of the derived conclusions. Therefore, the PTK method provides the experimental basis for modelbased derivation of reaction kinetics valid under dynamic conditions. The applicability of the methodology is demonstrated for the methanation reaction chosen as an example process for heterogeneously catalyzed reactions relevant for chemical energy storage purposes.
\end{abstract}

\section{Keywords}

Method development, Unsteady-state experiments, Dynamic kinetic data, Heterogenous catalysis, Gas phase reaction, CO hydrogenation 


\section{Introduction}

The transition from a fossil-based energy sector to an energy supply based on renewables leads indispensably to fluctuations in the energy production [1-3]. In order to dampen these fluctuations, buffer systems need to be integrated into the energy supply chain, which are based on storing electrical, chemical or physical energy. One attractive option for chemical energy storage is the Power-to-Gas processes (PtG), which allows to convert electrical into chemical energy by electrolysis yielding hydrogen. Subsequently hydrogen can be further converted with carbon oxides into methane, which can directly be stored and distributed in the existing natural gas grid [3]. Due to cost and transport reasons efficient local PtG units are beneficial, allowing an implementation in proximity of the energy and carbon source [3-5]. In the same vein cost-efficient local PtG units are equipped with small buffer capacities to dampen feed fluctuations, which limits the possibility to ensure a steady-state operation of the chemical reactor. Hence, fluctuations of the power supply propagate into the chemical reactor and an unsteady-state operation of the methanation reactor is necessary [1-3].

Therefore, an efficient and safe operation of the methanation reactor is required under unsteady-state conditions, which needs a deep understanding of the underlying kinetic process dynamics at different length scales [1]. The challenge becomes evident considering the fact that the underlying balance equations for describing the reactor behavior lead to a system of non-linearly coupled ordinary differential equations, even for the most simplifying assumptions. More realistic assumptions even lead to a system of partial differential equations, e.g. for distributed systems. On top of this the reactor has to be distinguished into three different scales, whose intrinsic dynamic behavior is rather independent of each other [6,7]. For illustration the reactor dynamics at the reactor or macro scale is determined by the fluid dynamics and usually expressed by the residence time distribution (RTD). At the particle or meso scale diffusion processes between the bulk flow and the external catalyst surface, as well as within the porous system affect the dynamics. At the catalyst surface or micro scale, the sorption and surface reaction processes determine the dynamics. Therefore, the characteristic steps in heterogeneously catalyzed reactions, i.e. film and pore diffusion, ad- and desorption of reactants as well as surface reaction, can directly be linked to the length scales and dynamic behavior. Under realistic operating conditions the dynamic reactor response is an interplay of all those kinetic processes. This leads to a severe challenge for determination of the intrinsic dynamics at each individual length scale from the cumulative reactor response. Therefore, the scales are usually studied separately from each other, which requires sophistically designed experiments, though, in order to avoid mutual interaction.

For the investigation of the processes at the catalyst surface under fluctuating feed gas mixtures several experimental methods already exist. Happel et al., Bennet and Biloen et al. developed the steady-state isotopic transient kinetic analysis (SSITKA) method [8-10], which is capable to determine the exchange rate and surface coverage of individual species [11]. Therefore, the isotopic composition of the reactants is changed, while the catalyst surface is assumed to remain in a quasi-steady-state [12]. Im- 
portantly, this assumption means that the reactions rates are unaffected by the transient change in isotopic composition and thus remain in steady-state. Additionally, an inert tracer is usually used to correct the residence time distribution of the reactants within the reactor [11]. The capabilities and limitations of SSITKA as well as modeling approaches were summarized by Ledesman et al. comprehensively [13]. Temporal analysis of products (TAP) measurements introduced by Gleaves et al. are capable to extract kinetic information by avoiding changes of the catalyst surface during the experiment $[14,15]$. Therefore, small amounts of reactants compared to the number of active sites are pulsed into the system. The catalytic system experiences only small perturbations and the catalyst surface remains rather unchanged during the experiment [14-16]. As these measurements are conducted with small catalyst particles under vacuum atmosphere only Knudsen diffusion determines the RTD. Thus, intrinsic kinetic data of the reaction network can be received, with the limitation that the system is far from realistic conditions. Another dynamic method introduced by Mori et al. [17] exploits the benefits of single pulses applied to a reaction system. A defined number of molecules is pulsed into a carrier gas stream and the response signal is either analyzed with respect to the propagation in the falling edge [17] or with respect to an internal standard. The latter was used by Friedland et al. to investigate the storage capacity of a catalyst under dynamic conditions $[18,19]$. These methods, however, need welldefined conditions for meaningful results and are based on a limited degree of deflection of the catalyst from its original state for a small period of time.

The chemical transient kinetics (CTK) method is based on a step-shaped change in the feed gas mixture and "track of the construction (build-up) or scavenging (backtransient) of the catalytically active phase as a function of time" [12]. Therefore, the gas phase composition upon step-change is measured as function of time and linked to ad-and desorption processes between the catalyst surface and the gas phase. Since an internal standard is used as well, the RTD of the reaction system can be measured in-situ, which allows to separate the RTD and the dynamic processes at the catalyst surface in the measured signal [20-22]. Furthermore, an external standard allows for derivation of quantitative information, as well [12]. Finally, CTK provides the possibility to derive the coverage degree as function of time using the "surface atom counting technique" [12], which basically corresponds to the elemental balance of the gas phase. Interestingly, CTK has been applied successfully to CO hydrogenation reactions, such as Fischer-Tropsch (FT) synthesis [23], exhibiting the capability of deriving mechanistic insights and even information on the chain growth probability [24,25]. The method, however, is demonstrated for ambient pressure only [12], which is identified as an important limitation by Athariboroujeny et al. [25], in particular for deducing the effect of operating pressure on the mechanistic pathways in FT reaction. Recently, Chen et al. applied a combination of CTK and SSITKA to deduce the mechanism of $\mathrm{CO}$ methanation and Fischer-Tropsch reaction for cobalt catalysts [26,27]. Consequently, all methods described above are used to analyze the dynamic processes at the catalyst surface (micro scale) by eliminating the transport processes at macro and meso scale, but all are limited to model conditions (i.e. ambient operating pressure or below). An experimental methodology applicable to realistic conditions and capable to 
link the transient response of real reactors with the dynamic processes at all length scales, is thus still lacking.

In the present contribution we therefore introduce the method of periodic transient kinetics (PTK), which allows the investigation of kinetic process dynamics at different length scales separately of each other. It is based on the CTK method recently emphasized by Raub et al. [12], but provides some important improvements. First of all, periodic step-changes are performed in order to enhance the reliability by statistical analysis of the limit cycle. Secondly, the PTK method is demonstrated at higher pressures, which allows to close the gap between model and realistic conditions in future. We focus on a detailed introduction of the experimental implementation and the quantitative evaluation approach of the molar flow rates derived from the measured gas phase composition as function of time. The applicability of the PTK method will be demonstrated for the methanation reaction as an example for heterogeneously catalyzed gas phase reactions but can also be transferred to more complex multiphase reactions, such as FT synthesis. Furthermore, the methodology is flexible to be applied to various reactor types.

Since the present contribution focusses on the introduction of the methodology, it is thus based on comprehensive explanations of the relevant terms, as well as procedures for experimental conduction and data evaluation. We therefore structured the paper as follows: Because the terms used for unsteady-state reactor operation are often used inconsistently, we define and classify dynamic processes and the related terminology first. In section 3 we discuss the challenges related to the performance of dynamic experiments under realistic conditions and describe the developed methodology in detail, which comprises the experimental setup and procedure, as well as the respective model-based data evaluation. Finally, the methodology is demonstrated for two examples in the context of the methanation process in section 4, namely the $\mathrm{CO}_{2}$ adsorption on $\mathrm{Al}_{2} \mathrm{O}_{3}$ and the unsteady-state $\mathrm{CO}$ methanation reaction using a $\mathrm{Ni} / \mathrm{Al}_{2} \mathrm{O}_{3}$ catalyst. The results of the latter example are briefly discussed in comparison to literature findings for illustration of the potential of the PTK methodology.

\section{Terminology}

In the field of dynamically operated chemical reactors and unsteady-state processes a variety of different terms are required, in order to precisely correlate the experimental observations with the underlying mechanisms. For sake of clarity those terms relevant to the PTK methodology introduced in the present study are briefly defined below. The PTK method can be classified as a forced unsteady-state process according to Matros et al. [28], since the unsteady-state behavior is induced by an external fluctuating input signal. In particular, a step-shaped change in the feed molar flow rate is used as input signal in the present study. According to the scope of the study, the system is investigated for examples in the context of the methanation reaction either by modeling and simulation or by experiments. Therefore, self-oscillating systems and other types and shapes of forced input signals are not in the focus here, but comprehensively summarized by different authors [28-32]. 
A dynamic process is characterized by time dependent state variables, such as temperature or concentration, of the inlet and outlet streams, as well as of the reactor volume. Note that for forced unsteady-state reactor operation the inlet stream is usually used as the forced input, while the outlet stream is referred to as the reactor response. Each state variable can either be in steady-state or in unsteady-state, which is distinguished by the time derivative being zero or non-zero, respectively. Upon disturbance at time zero a state variable deflects from the initial state followed by a transient phase [31], which depends on the type of the disturbance and the dynamic behavior of the process. Therefore, the term 'unsteady-state' is defined strictly mathematical, while 'transient behavior' defines the trajectory of the variable in time.

The type respectively periodicity of a temporal change is usually classified as follows (for illustration of different system behaviors see Table 1): An aperiodic signal is characterized by a transient change of a variable from an initial to a final steady-state. $A$ periodic signal, instead, changes from the initial state to a second state and finally reaches the initial state again, which can be repeated multiple times. Note, that the response induced by a consecutive positive and negative step change, such as applied in the CTK method [21,22], is designated with the terms build-up and back-transient phase, respectively.

The periodic operation allows the system to reach a limit cycle (LC), which is characterized by an invariant behavior for each period [33] and which is particularly advantageous for the evaluation of the dynamic response [18]. It has to be mentioned that the term LC refers to the response of a system only and characterizes its periodicity. The characteristics of a LC depends on the shape and cycle period $\tau$ (inverse frequency) of the input signal, as well as on the characteristic relaxation time $\tau_{\text {res }}$ of the system, which can be determined from the system response [34,35]. According to literature [34-36] three types of the response being in a LC can be distinguished with respect to the $\tau / \tau_{\text {res }}$ ratio. For large $\tau / \tau_{\text {res }}$ ratios the response is in quasi-steady-state (qss), which means that the system response is fast compared to changes in the input signal. The system, thus, is nearly in a steady-state depending on the current input signal at each point in time. In the opposite case of small $\tau / \tau_{\text {res }}$ ratios the relaxed steady-state (rss) is reached, which is characterized by fast changes of the forced input and a slow reaction by the inertial system. This leads to diminishing amplitudes of the response with increasing frequencies of the forced input. For high frequencies the system response even appears to be in steady-state, though it is still changing with time, since the response amplitude is smaller than the measurable threshold. Note that the apparent steady-state may differ from that under true steady-state conditions [34]. The fulltransient state (fts) is reached for $\tau / \tau_{\text {res }} \approx 1$ between both boundary cases, where the response depends strongly on the applied frequency. Interestingly, the information content is high in this region [34], which makes it attractive for fundamental research. The main challenges arise from the strong non-linear relation between input and response, which results in a high complexity of the experimental procedure and data evaluation. Furthermore, the applied frequencies to reach the fts region can be quite high, which requires a high temporal resolution of the analytical system and demanding switching for periodic input signals. 
Table 1: Illustration of periodicity for different types of system responses during step-shaped dynamic experiments with the following abbreviations: steady-state (SS), unsteady-state (US), transient process (TP), build-up (BU), back-transient (BT), limit cycle (LC), quasi steady-state (qss), relaxed steady-state (rss), full transient-state (fts).

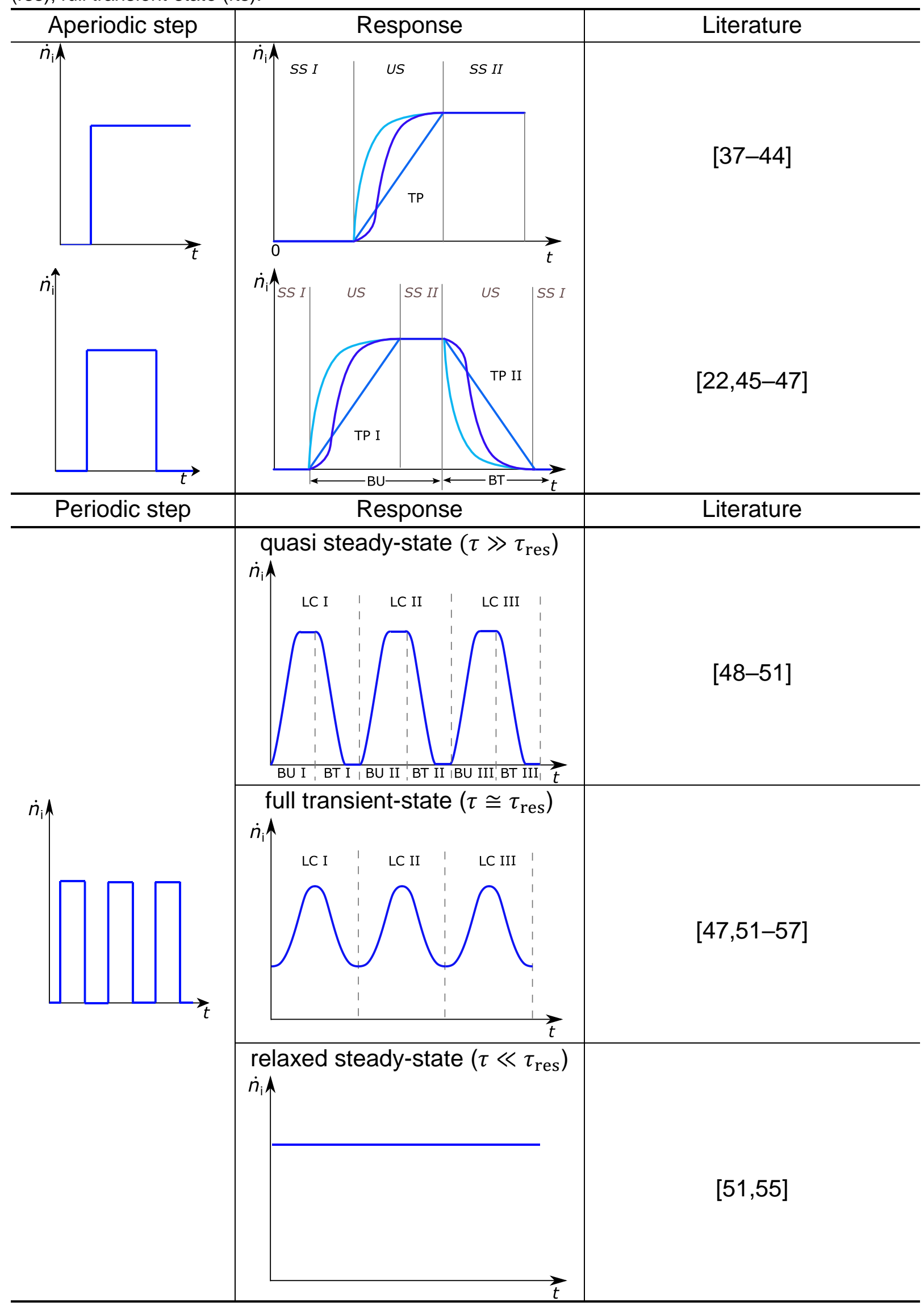


Table 1 illustrates the classification of forced input signals according to the periodicity and indicates references to the application in the context of the unsteady-state $\mathrm{CO}$ and $\mathrm{CO}_{2}$ methanation. The aperiodic step changes are mainly used to investigate the transient behavior of the reactants and to gain further insights into the underlying surface processes and reaction mechanisms $[22,37,43,53,58]$. The forced periodic operation, though, has been investigated for various reaction systems in order to achieve higher conversion $[28,29,32,59-62]$ or selectivity $[29,63]$, while an increase in catalyst stability [32] has been reported for different reaction systems, as well. With emphasis on methanation experimental studies on forced periodic operation are performed aiming at kinetic investigations [47,53], as well as process intensification for $\mathrm{CO}[47,49,57]$ and $\mathrm{CO}_{2}[54,64]$ methanation. In addition to that theoretical approaches are introduced for the evaluation of the higher frequency response $[56,61,65]$. All these studies concentrate on the qss or $\mathrm{fts}$ region as the information content is high and experimental realization is feasible with reasonable effort.

\section{Experimental Implementation}

\subsection{Challenges for unsteady-state experiments}

With emphasis on periodic step-shaped experiments for the methanation reaction following real effects contribute to the observed signal and have to be considered in design of experimental procedures and data evaluation. At the macro scale an ideal step change in the composition is hardly possible, due to the duration of the switching event between two compositions. Furthermore, the RTD in the piping between the switching valve and the catalyst bed, as well as between the catalyst bed and the detector of the analytics may deviate from ideal plug flow behavior and thus affects the intrinsic response of the catalyst bed. In particular, laminar flow profiles can be expected given by the small diameters of the piping in lab-scale equipment and thus small Reynolds numbers. Finally, complex real effects on the RTD within the catalyst bed render the separation of the dynamics at each characteristic length scale more difficult. Specifically, axial and radial gradients in composition, flow rate and pressure induce dispersion effects and thus deviation from ideal plug flow behavior. The pressure drop over the fixed-bed differs for different feed gas compositions, as well. For methanation, in particular, the chemical reaction also causes volume contraction and thus changes in the volumetric flow rate can occur. At the meso scale heat and mass transfer limitations between the fluid bulk and the external catalyst surface, as well as within the porous pellet, lead to the formation of pronounced temperature and concentration profiles, which superimpose the dynamic behavior of the processes at the micro scale. At the micro scale the main challenges arise from slow dynamic processes, such as catalyst deactivation, which have to be separated from the very fast processes involved in the chemical surface reaction. In addition to that chromatographic effects may occur at all scales upon step-changes in the inlet composition [22,66,67].

\subsection{Experimental Setup}

The experimental setup is adapted from the CTK method [20-22,45,46]. A flowsheet of the experimental setup is shown in Figure 1 and the corresponding 3D model in 
Figure 2. Note, that the colors given in brackets behind the described parts of the experimental setup below correspond to the colors in Figure 1 and Figure 2. The setup is equipped with two independent gas lines (red and blue). By means of a pressure actuated high speed valve (Fitok, BOSS-4C) (orange) one gas line is fed into the reactor (green), while the other is directly injected into the bypass line (grey). With the high speed valve the switching process takes less than $0.2 \mathrm{~s}$, which is below the temporal resolution of the MS analytics $(0.5 \mathrm{~s}$, see below). This provides a nearly ideal step change (see Appendix, Figure S9). The gases $\mathrm{H}_{2}$ (5.0 purity, MTI), $\mathrm{CO} / \mathrm{Ar}$ (90 vol.$\% \mathrm{CO}$ of 3.8 purity in Ar of 5.0 purity, Air Liquide), $\mathrm{CO}_{2}$ (4.8 purity, MTI), $\mathrm{Ar}$ (5.0 purity, $\mathrm{MTI}$ ) and He (5.0 purity, MTI) are supplied via mass flow controllers (MFC) (EL-FLOW Prestige, Bronkhorst), without further purification. Note, that Ar is used as an internal standard (IS) for all experiments.

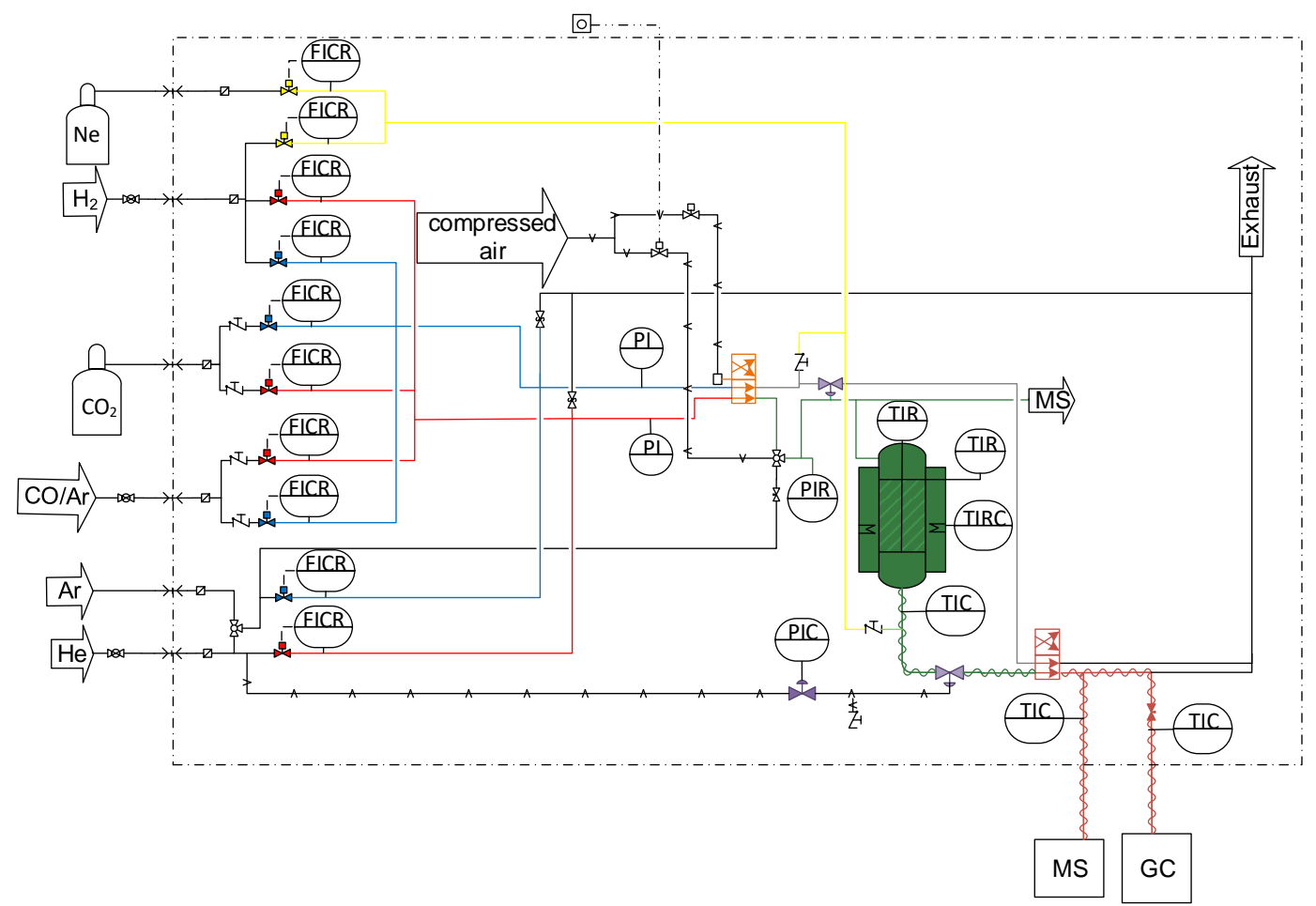

Figure 1: Flowsheet of the experimental setup to investigate heterogeneously catalyzed gas-phase reactions under unsteady-state conditions (color code is used for explanation in the text and corresponds to Figure 2).

All lines consist of $1 / 8$ " tubing (inner diameter $2 \mathrm{~mm}$ ) in order to minimize the volume of the reactor periphery. The section between the switching valve and reactor exhibits a volume of $3 \mathrm{~mL}$, only and is equipped with an additional analytic port directly at the reactor inlet (light green). This allows to measure the deviation of the switching event from an ideal step and thus the apparent RTD of the switching event, which is considered for the data evaluation (see Appendix, Figure S9).

The experiments are conducted in a stainless-steel fixed-bed reactor (green) with an inner diameter of $4.5 \mathrm{~mm}$ and a total length of $30 \mathrm{~cm}$, which results in a total volume of $7 \mathrm{~mL}$. The reactor is equipped with a concentric $1 / 16$-inch capillary containing a movable thermocouple (type $\mathrm{K}, \mathrm{TMH}$ ). The heating is accomplished by 4 heating cartridges (200 W Firerod, Telemeter Electronic) placed equally spaced inside an aluminum jacket, which provides an axial isothermal zone of around $10 \mathrm{~cm}$. The catalyst 
particles are fractionated in a size range of 150 to $200 \mu \mathrm{m}$ and are diluted with twice the amount of inert particles $\left(200 \mu \mathrm{m}, \mathrm{Al}_{2} \mathrm{O}_{3}\right.$, Sasol Puralox) of the same size. Therefore, internal heat and mass transfer limitations can be neglected, which was verified in our previous paper under identical conditions by applying the Mears, Anderson, and Weisz-Prater criteria [68]. The catalyst bed with a total length of $2 \mathrm{~cm}$ is placed in the center of the isothermal section, which ensures isothermal conditions for temperatures up to $600 \mathrm{~K}$ with deviations of $< \pm 1 \mathrm{~K}$. The packing is fixed inside the reactor by solid, non-porous glass particles (silica beads, häberle) of the same particle size and glass wool (silica wool, VWR). The total length of the packing sums up to around $10 \mathrm{~cm}$. Non-porous glass is used, since it provides a small surface area for potential interaction with the gas species. Furthermore, solid glass particles reduce the gas holdup in the reactor, as well. RTD measurements are performed, which confirm minor deviation from ideal plug flow behavior within the packed fixed-bed reactor (see Appendix, Figure S9).

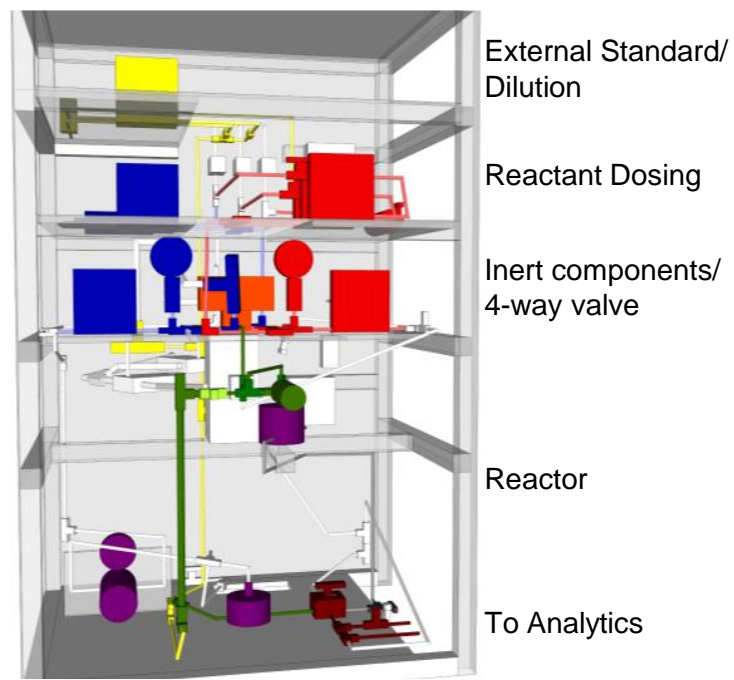

Figure 2: 3D-model of the experimental setup for the investigation of heterogeneously catalyzed gasphase reactions (color code is used for explanation in the text and corresponds to Figure 1).

The operating pressure is controlled by two back pressure regulators (violet, LF1, Equilibar). The working principle is based on an equilibrium of forces between a flowing gas and a pilot gas at a membrane, which ensures negligible pressure fluctuations even at low flow rates. One regulator is placed at the reactor outlet and the second in the bypass line. In order to reduce pressure spikes during the switching between both gas lines to about 50 mbar, the reactor inlet pressure is used as pilot pressure for the bypass-line. At the reactor outlet a mixture of $\mathrm{H}_{2}$ (5.0 purity, MTI) and $\mathrm{Ne}$ (5.0 purity, MTI) (yellow line) is dosed via MFCs (EL-FLOW Prestige, Bronkhorst). The external standard (ES) mixture containing $\mathrm{Ne}$ as $\mathrm{ES}$ and additional $\mathrm{H}_{2}$ is fed directly at the reactor outlet in order to reduce the residence time between outlet and analytics below the temporal resolution of the analytics. The tubing downstream the reactor is heated to $70{ }^{\circ} \mathrm{C}$ to prevent condensation of $\mathrm{H}_{2} \mathrm{O}$. Note that the maximum $\mathrm{H}_{2} \mathrm{O}$ partial pressure is significantly below the vapor pressure, due to the low conversion and dilution with inert gas.

The analytics consist of a process mass spectrometer (MS) (Cirrus 3-XD, MKS), which allows to analyze the mass-to-charge ratios $2\left(\mathrm{H}_{2}\right), 4(\mathrm{He}), 15\left(\mathrm{CH}_{4}\right), 18\left(\mathrm{H}_{2} \mathrm{O}\right), 20(\mathrm{Ne})$, 
$28\left(\mathrm{CO}\right.$ and $\left.\mathrm{CO}_{2}\right), 40(\mathrm{Ar})$ and $44\left(\mathrm{CO}_{2}\right)$ quantitatively with a temporal resolution of $0.5 \mathrm{~s}$ after calibration. The mass-to-charge ratios $26\left(\mathrm{C}_{2} \mathrm{H}_{6}\right)$ and $43\left(\mathrm{C}_{3} \mathrm{H}_{8}\right)$ are monitored qualitatively, as well. An auxiliary gas chromatograph (GC-2010, Shimadzu with RT-Q-Bond pre-column and molecular sieve $5 \mathrm{~A}$ column), equipped with a thermal conductivity and flame ionization detector, is used to calibrate the MS results for $\mathrm{CO}, \mathrm{CO}_{2}$, $\mathrm{Ar}$, and hydrocarbons up to $\mathrm{C}_{3}$ under steady-state conditions. The analytics allow to minimize the error in the carbon mass balance based on MS measurements to $<5 \%$ under steady-state and to $<10 \%$ under unsteady-state conditions. Note, that higher hydrocarbons are negligible and not detected by means of MS, as indicated by steadystate experiments using the same catalyst and similar conditions previously reported [68].

\subsection{Evaluation with the periodic transient kinetics method}

\subsubsection{Implications of an internal and external standard}

The RTD of a reactor equipped with porous catalyst pellets is affected by transport processes at both the macro and the meso scale, since dispersion in the convective flow and diffusion in the porous structure contribute to the overall response. Since the RTD of the internal standard (IS) measured in-situ is assumed to be representative $[12,19,22]$, it allows to provide each experimental data set together with the individual residence time behavior. If those transport phenomena are not selective towards certain components, the RTD is identical for all components $i$ and is just scaled with a proportional factor $C$ according to eq. (1), where $\dot{n}_{i}$ refers to the measured molar flow rate of component $i$ as function of time. Hence, the obtained molar flow rate at the reactor outlet $\dot{n}_{i, \text { out }}$ of any compound $i$ can be plotted against $\dot{n}_{\mathrm{IS}, \text { out }}$ providing a linear dependency, if the above-mentioned assumptions are fulfilled. In other words, any deviation in experimental data from eq. (1) indicates compound selective effects in the system. For the example of heterogeneously catalyzed reactions, being in the focus of the present contribution, those effects are mainly caused by the interaction of compound $i$ with the solid surface. In particular, dissipation of species $i$ from the gas phase $\left(\dot{n}_{i, \text { out }} / \dot{n}_{\mathrm{IS}, \text { out }}<C\right)$ indicates adsorption at the solid surface, while appearance $\left(\dot{n}_{i, \text { out }} / \dot{n}_{\mathrm{I}, \text { out }}>C\right)$ may be caused by desorption.

$$
\frac{\dot{n}_{i, \text { out }}(t)}{\dot{n}_{\mathrm{IS}, \text { out }}(t)}=C=\text { const. }
$$

The ES is required to obtain the molar flow rates from MS data, in order to derive the material balance for all compounds $i$ quantitatively [12]. The ES also allows to identify unwanted fluctuations in the volumetric flow rate, in particular during the switching event between two different feed gas compositions, which might cause pressure fluctuations at the reactor inlet. Therefore, the ES is dosed into the reactor outlet stream with a constant molar flow rate $\dot{n}_{\mathrm{ES}}$ and the molar fraction $x_{\mathrm{ES}}$ is measured over time by the MS, in order to derive the outlet molar flow rate $\dot{n}_{\text {out }}$ according to eq. (2). The comparison of the ES molar fraction under reaction conditions $x_{\mathrm{ES}}$ with the reference $x_{\mathrm{ES} \text {,ref }}$ according to eq. (3) thus indicates any change in the volumetric flow rate at the reactor outlet. For all experiments $x_{\mathrm{ES} \text {,ref }}$ is obtained under absence of chemical reac- 
tion. With parameter $\alpha$ the molar outlet flow rate $\dot{n}_{i, \text { out }}$ of species $i$ can then be calculated with eq. (4). Here $x_{i, \text { out }}$ accounts for the measured molar fraction of species $i$ at the reactor outlet and $\dot{V}_{\mathrm{in}, \mathrm{STP}}$ for the overall volumetric flow rate at the reactor inlet. While $p_{\text {STP }}$ and $T_{\text {STP }}$ refer to standard temperature and pressure (STP), $R$ is the universal gas constant.

$$
\begin{gathered}
x_{\mathrm{ES}}(t)=\frac{\dot{n}_{\mathrm{ES}}}{\dot{n}_{\text {out }}(t)} \\
\alpha(t)=\frac{x_{\mathrm{ES}, \text { ref }}}{x_{\mathrm{ES}}(t)}=\frac{\dot{n}_{\text {out }}(t)}{\dot{n}_{\text {out,ref }}} \\
\dot{n}_{i, \text { out }}(t)=\frac{\alpha(t) x_{i, \text { out }} p_{\mathrm{STP}} \dot{V}_{\text {in,STP }}}{R T_{\mathrm{STP}}}
\end{gathered}
$$

\subsubsection{State space plot}

The graphical representation of eq. (1) is provided by the state-space plot, which displays the response of component $i$ as a function of that for the internal standard Ar in the present contribution. For heterogeneously catalyzed systems the state-space plot can unravel interactions between a gaseous component and the solid surface by sorption processes, for instance. Note that the state-space plot is not limited to specific types of transient signals and rather complements the typical plot of transient signals as function of time.

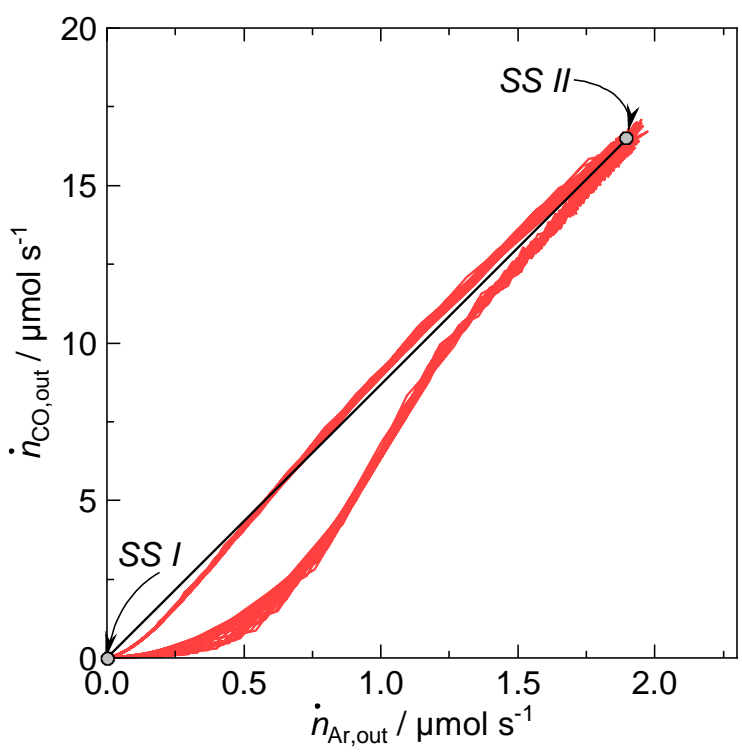

Figure 3: Measured outlet molar flow rates $\dot{n}_{i, \text { out }}$ of $\mathrm{CO}$ and the internal standard $\mathrm{Ar}$ in the state-space plot for the forced periodic $\mathrm{CO}$ methanation reaction according to example II; the average LC is displayed in red; the black line represents eq. (1); the steady-states are indicated as SS I and SS II.

Figure 3 represents a typical state-space plot for a periodic experiment and depicts the outlet molar flow rate of $\mathrm{CO} \dot{n}_{\mathrm{CO}, \text { out }}$ as function of the internal standard $\mathrm{Ar} \dot{n}_{\mathrm{Ar}, \text { out }}$. The individual LCs used for the calculation of the average LC are indicated in red. The state-space plot thus allows a simple visual evaluation of the LC and possible deviations. Furthermore, both steady-states are reduced to one point for each in this plot, since the ratio between the outlet molar fluxes of component $i$ and the internal standard 
does not change with time during. Therefore, the transient processes during the periodic experiments become more prominent in the state-space plot and are thus easier accessible.

\subsubsection{Derivation of the average limit cycle from experimental data}

The PTK methodology provides periodic data of the system response, since the input signal is periodic. Considering that the transient outlet molar flow $\dot{n}_{i, \text { out }}$ of component $i$ is equivalent to the system response, it provides the experimental data basis for further analysis. The key property of the LC is that each point within a period $0 \leq t \leq \tau$ of the duration $\tau$ is reached in each period $N_{m}$ and that the corresponding response $\dot{n}_{i, m \text {,out }}$ is identical. We also assume that each measured data is affected by noise. Therefore, the results obtained within the LC are averaged over a certain number of periods $N_{\Theta}$ according to eq. (5), in order to improve the signal-to-noise ratio by statistical analysis. The obtained average molar flow rate at the reactor outlet $\overline{\dot{n}}_{i, \text { out }}$ thus corresponds to the average LC. In addition, the variance $\Delta \overline{\dot{n}}_{i, \text { out }}^{2}$ of the average LC can be calculated by eq. (6), which can further be used to determine confidence intervals of the LC.

$$
\begin{gathered}
\overline{\dot{n}}_{i, \text { out }}(t)=\frac{1}{N_{\Theta}} \sum_{m=1}^{N_{\Theta}} \dot{n}_{i, m, \text { out }}(t) \\
\Delta \overline{\dot{n}}_{i, \text { out }}^{2}(t)=\frac{1}{N_{\Theta}} \sum_{m=1}^{N_{\Theta}}\left[\dot{n}_{i, m, \text { out }}(t)-\overline{\dot{n}}_{i, \text { out }}(t)\right]^{2}
\end{gathered}
$$

Figure 4a shows the periodic response of the system in form of the $\mathrm{CH}_{4}$ outlet molar flow rate as an example. In total the response for 50 periods is shown of which the last 25 periods (in red) except the very last are used for averaging, since the activity loss over those periods is less than $3 \%$. Figure $4 \mathrm{~b}$ depicts the corresponding average LC together with the standard deviation (red shaded area).
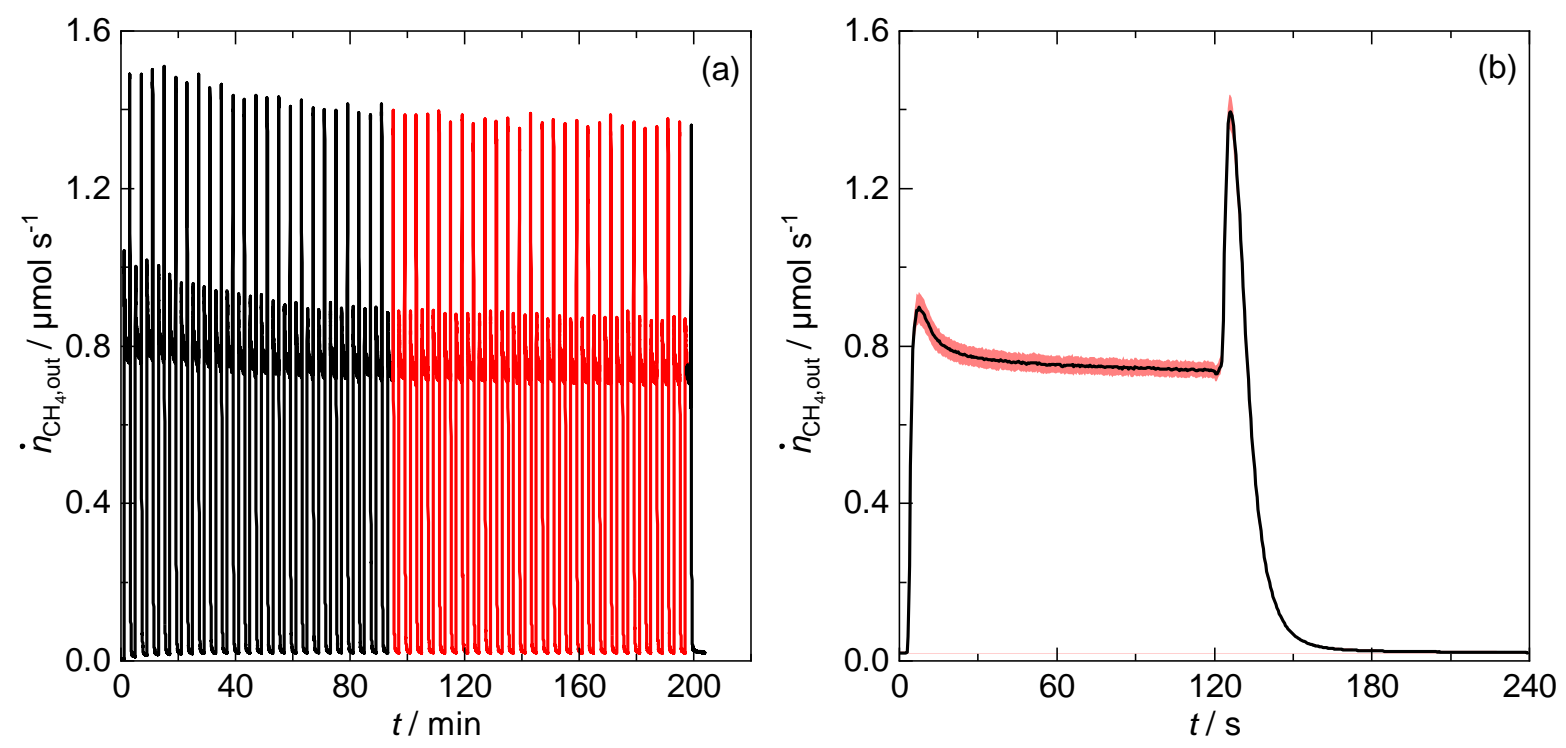

Figure 4: System response in form of the measured $\mathrm{CH}_{4}$ molar flow rate over 50 periods (a) of switching between $\mathrm{CO} / \mathrm{H}_{2}$ and $\mathrm{H}_{2}$ according to example II; averaged periods are displayed in red; corresponding average LC (b) with standard deviation in red. 


\subsubsection{Calculation of transient molar flow rates}

The deviation of the system response for component $i$ from the RTD can be evaluated quantitatively by calculating the transient molar flow rates, which are identical to the net surface flows defined in the CTK method [12]. Therefore, the observed response in form of the measured outlet molar flow rate $\dot{n}_{i, \text { out }}$ of component $i$ during a transient process is assumed to be a superposition of two contributions according to eq. (7). The first contribution originates from the overall RTD, which results in the corresponding molar flow rate $\dot{n}_{i, \mathrm{RTD}}$. The second contribution quantifies the transient molar flow rate $\dot{n}_{i, \text { trans }}$ and thereby the deviation from the RTD during the transient process. Figure 5 visualizes this equation for $\mathrm{CH}_{4}$ as an example. It has to be mentioned that this approach requires the LC as necessary condition, since thereby $\dot{n}_{i \text {,trans }}$ corresponds to the deviation within one period only. If the LC is not achieved also previous deviations may accumulate in $\dot{n}_{i, \text { trans }}$, which falsifies the analysis. Furthermore, it has to be mentioned that the transient molar flow rate is generally considered as a temporal source or sink term for each component, irrespective of the specific reason. Even though the main reason is probably the interaction of component $i$ with the catalyst surface by adand desorption, chemical reaction or irreversible processes may also contribute to $\dot{n}_{i, \text { trans }}$.

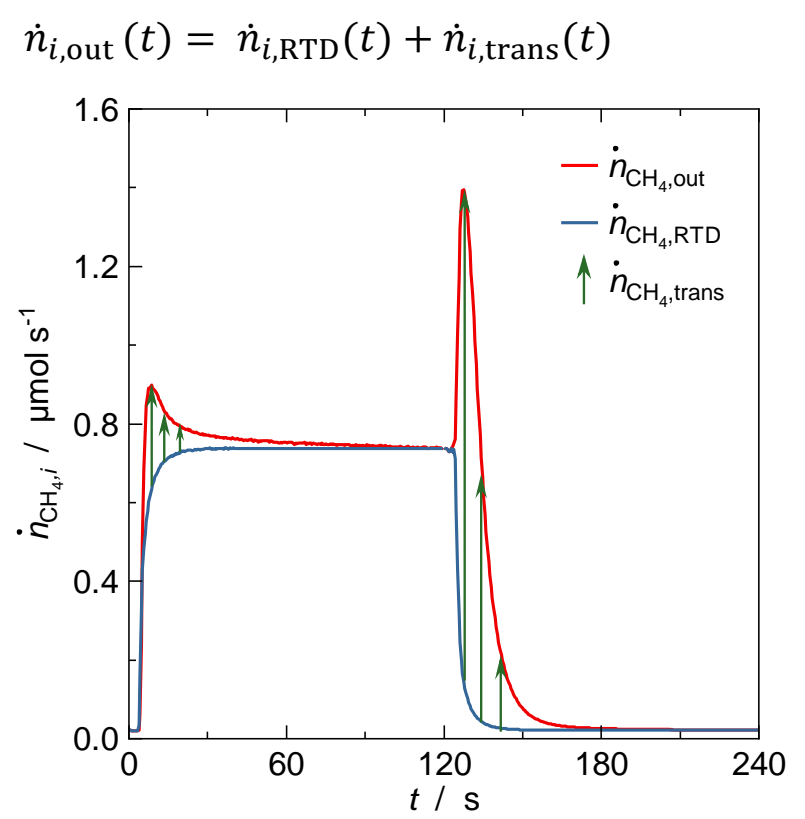

Figure 5: System response in form of the measured $\mathrm{CH}_{4}$ outlet molar flow rate $\dot{n}_{\mathrm{CH}_{4}, \text { out }}$, the calculated values $\dot{n}_{\mathrm{CH}_{4}, \mathrm{RTD}}$ for the contribution of the RTD and the transient molar flow rate $\dot{n}_{\mathrm{CH}_{4} \text {, trans }}$ for the forced periodic $\mathrm{CO}$ methanation reaction according to example II.

The contribution of the RTD for each component $\dot{n}_{i, \mathrm{RTD}}$ is calculated by a function characterizing the RTD of the internal standard $F_{\mathrm{Ar}}$ and the outlet molar flow rates for each component at the steady-states for both feed gas mixtures $\dot{n}_{i, \mathrm{out}, \mathrm{ss}, 1}$ and $\dot{n}_{i, \mathrm{out}, \mathrm{ss}, 2}$, according to eq. (8). Therefore, the function $F_{\mathrm{Ar}}$ is derived from the outlet molar flow rates of the internal standard $\operatorname{Ar} \dot{n}_{\mathrm{Ar} \text {,out }}$ normalized with the flow rates at both steady-states (see eq. (9)).

$$
\dot{n}_{i, \mathrm{RTD}}(t)=\left(\dot{n}_{i, \mathrm{out}, \mathrm{ss}, 2}-\dot{n}_{i, \mathrm{out}, \mathrm{ss}, 1}\right) F_{\mathrm{Ar}}(t)+\dot{n}_{i, \mathrm{out}, \mathrm{ss}, 1}
$$




$$
F_{i}(t)=\frac{\dot{n}_{i, \text { out }}(t)-\dot{n}_{i, \text { out }, \text { ss }, 1}}{\dot{n}_{i, \text { out }, \text { ss }, 2}-\dot{n}_{i, \text { out }, \text { ss }, 1}}
$$

The steady-state is assumed to be achieved, if no temporal gradients in the signal occur, which corresponds to the mathematical definition of time derivatives being zero. Under real conditions, however, long term processes monotonical affecting the response, such as catalyst deactivation, have to be considered. Since the investigation of those processes do not require periodic experiments, due to their long term and irreversible nature, a certain but very small temporal gradient in the signal is acceptable, depending on the individual case. In our case steady-state conditions are reached for the last $5 \mathrm{~s}$ in each half period. Hence, the respective outlet molar flow rates are used for the calculation of $\dot{n}_{i, \mathrm{out}, \mathrm{ss}, 1}$ and $\dot{n}_{i, \mathrm{out}, \mathrm{ss}, 2}$ by averaging.

The transient molar flow rates for each component can be applied in order to derive transient elemental balances, as shown for the carbonaceous species in eq. (10). For negligible formation of higher hydrocarbons $\left(\mathrm{C}_{2+}\right)$, eq. (10) allows to calculate the amount of carbon stored at or released from the surface during the build-up and backtransient phase after integration over both half periods. Note, that the modification of carbon cannot be distinguished based on this equation without further surface specific analysis. In particular, various adsorbed carbon containing species may be present together with elemental carbon modifications and further carbon compounds [58].

$$
\dot{n}_{\mathrm{C}, \text { trans }}(t)=\dot{n}_{\mathrm{CO} \text {,trans }}(t)+\dot{n}_{\mathrm{CO}_{2} \text {,trans }}(t)+\dot{n}_{\mathrm{CH}_{4}, \text { trans }}(t)
$$

It is noteworthy, that the proper choice of the experimental conditions is of eminent importance for calculation and interpretation of the transient molar flow rates. Care must especially be taken regarding the signal-to-noise ratio expressed by the relative transient molar flow rate $\dot{n}_{i, \text { trans }} / \dot{n}_{i, \text { out }}$. In particular, the transient molar flow rate needs to be distinguishable from the total molar flow rate of the respective component despite of the errors in the measured data and the mass balance.

The determination of the transient molar flow rate by the PTK method allows to link the analysis of the gas phase composition in continuous systems with the molar amount of adsorbed species at the surface measured with respective experimental operando methods (e.g. diffuse reflectance infrared fourier transform spectroscopy, DRIFTS) quantitatively using material balances as follows. The transient molar flow rate $\dot{n}_{h, \text { trans }}$ of an element $h$ can be applied for calculation of the molar amount of substance of that element stored at the catalyst surface $n_{h, \text { surf }}$, according to the elemental balance shown in eq. (11). The respective component balance (eq. (12)) requires to consider the amount of substance converted in a surface reaction $R_{j, \text { surf }}$ in addition to the transient molar flow rate $\dot{n}_{h \text {,trans }}$ of component $i$, in order to calculate the amount of this component stored at the surface $n_{i, \text { surf }}$. The stoichiometric coefficient $v_{i, j}$ describes the stoichiometry of the adsorbed species only and equals zero for non-adsorbed components. Eq. (12) therefore allows to deduce reaction kinetics under dynamic conditions, since it links model-based evaluation of experimental data with the transient surface reaction rates. The challenge is that the involved surface species and surface reactions depend on the specific reaction mechanism, which is not known a priori in most cases. Therefore, an iterative approach is meaningful by building up the complexity of the 
mechanism until the prediction of the model agree with the transient measurement results of gaseous and surface species. Eq. (13) connects the elemental balances with those of the components, using the number of atoms of element $h$ in component $i$ expressed by $\beta_{h, i}$. Note that surface coverages can be obtained from the molar amount of substance stored at the catalyst surface, if the number of sorption sites is known.

$$
\begin{gathered}
\frac{d n_{h, \text { surf }}}{d t}=-\dot{n}_{h, \text { trans }}(t) \\
\frac{d n_{i, \text { surf }}}{d t}=-\dot{n}_{i, \text { trans }}(t)+\sum_{j} v_{i, j} R_{j, \text { surf }}(t) \\
n_{h}=\sum_{i} \beta_{h, i} n_{i} \quad \text { and } \quad \dot{n}_{h}=\sum_{i} \beta_{h, i} \dot{n}_{i}
\end{gathered}
$$

\subsection{Experimental procedure for demonstrating examples}

For the examples presented in this study the feed gas composition is switched 50 times either between $\mathrm{H}_{2} / \mathrm{He}\left(50 / 50\right.$ by volume) and $\mathrm{CO}_{2} / \mathrm{Ar} / \mathrm{H}_{2} / \mathrm{He}(10 / 1 / 40 / 49$ by volume) with a cycle period of $90 \mathrm{~s}$ for example I or between $\mathrm{H}_{2} / \mathrm{He}(40 / 60$ by volume) and $\mathrm{CO} / \mathrm{Ar} / \mathrm{H}_{2} / \mathrm{He}$ (10/1/40/49 by volume) with a cycle period of $240 \mathrm{~s}$ for example II. $\mathrm{Ar}$ is chosen as the internal standard for the $\mathrm{CO}_{x}$ species and $\mathrm{H}_{2} \mathrm{O}$, since it provides a similar diffusion coefficient and viscosity and is thus assumed to exhibit a representative RTD. The strong dilution with $\mathrm{He}$ is justified by the similarity to the physical properties of $\mathrm{H}_{2}$, the main component in the gas phase due to stoichiometric reasons. Therefore, the physical properties of all gas mixtures can be assumed to be rather similar, which provides the basis for a similarity in fluid dynamics in the system and thus in RTD. The

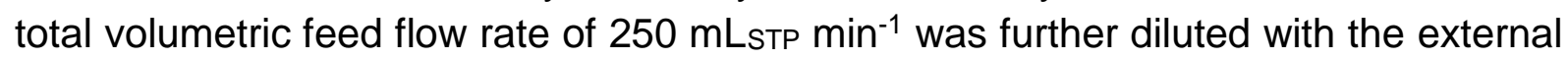
standard mixture after the reactor outlet consisting of $\mathrm{H}_{2} / \mathrm{Ne}\left(245{\mathrm{mLsTP} \mathrm{min}^{-1} / 5 \mathrm{mLsTP}}^{-1}\right.$ $\mathrm{min}^{-1}$ ), which reduces the residence time between the reactor outlet and the analytics section to below the temporal resolution of the MS.

The $\mathrm{CO}_{2}$ adsorption experiment of example I is conducted with $100 \mathrm{mg} \mathrm{Al}_{2} \mathrm{O}_{3}$ particles (Puralox, Sasol) with a particle size of 150-200 $\mu \mathrm{m}$. The methanation experiments from example II are conducted with $50 \mathrm{mg}$ of a $5 \mathrm{wt}-\% \mathrm{Ni} / \mathrm{Al}_{2} \mathrm{O}_{3}$ catalyst of the same size diluted with $100 \mathrm{mg} \mathrm{Al}_{2} \mathrm{O}_{3}$ particles (Puralox, Sasol) at a temperature of $556 \mathrm{~K}$ and a pressure of 2 bar, which provides almost full conversion of the carbon oxides in equilibrium [69]. Furthermore, the reactor is operated under differential conditions in order to neglect the impact of concentration gradients by keeping the carbon oxide conversion below $20 \%$ in all experiments [70]. Catalyst aging, e.g. due to deactivation, is monitored based on the steady-states and can be ruled out in the reported experiments $[71,72]$.

\section{Examples for method application}

\subsection{Example I: $\mathrm{CO}_{2}$ Adsorption}

For the example of $\mathrm{CO}_{2}$ adsorption at $\mathrm{Al}_{2} \mathrm{O}_{3}$ surface Figure 6a displays the observed system response in form of the measured outlet molar flow rate of $\mathrm{CO}_{2} \dot{n}_{\mathrm{CO}_{2} \text {,out. }}$ In 
addition, the theoretical response $\dot{n}_{\mathrm{CO}_{2}, \mathrm{RTD}}$ is shown as well, which is expected from pure RTD according to eq. (8). Figure $6 \mathrm{~b}$ depicts the transient molar flow rate $\dot{n}_{\mathrm{CO}_{2} \text {,trans }}$, while Figure $6 \mathrm{c}$ shows the respective state-space plot for $\mathrm{CO}_{2}$. Due to the absence of catalytical active sites, the deviation of the $\mathrm{CO}_{2}$ response from the RTD can be attributed to interaction of $\mathrm{CO}_{2}$ with the solid surface by ad- and desorption processes.
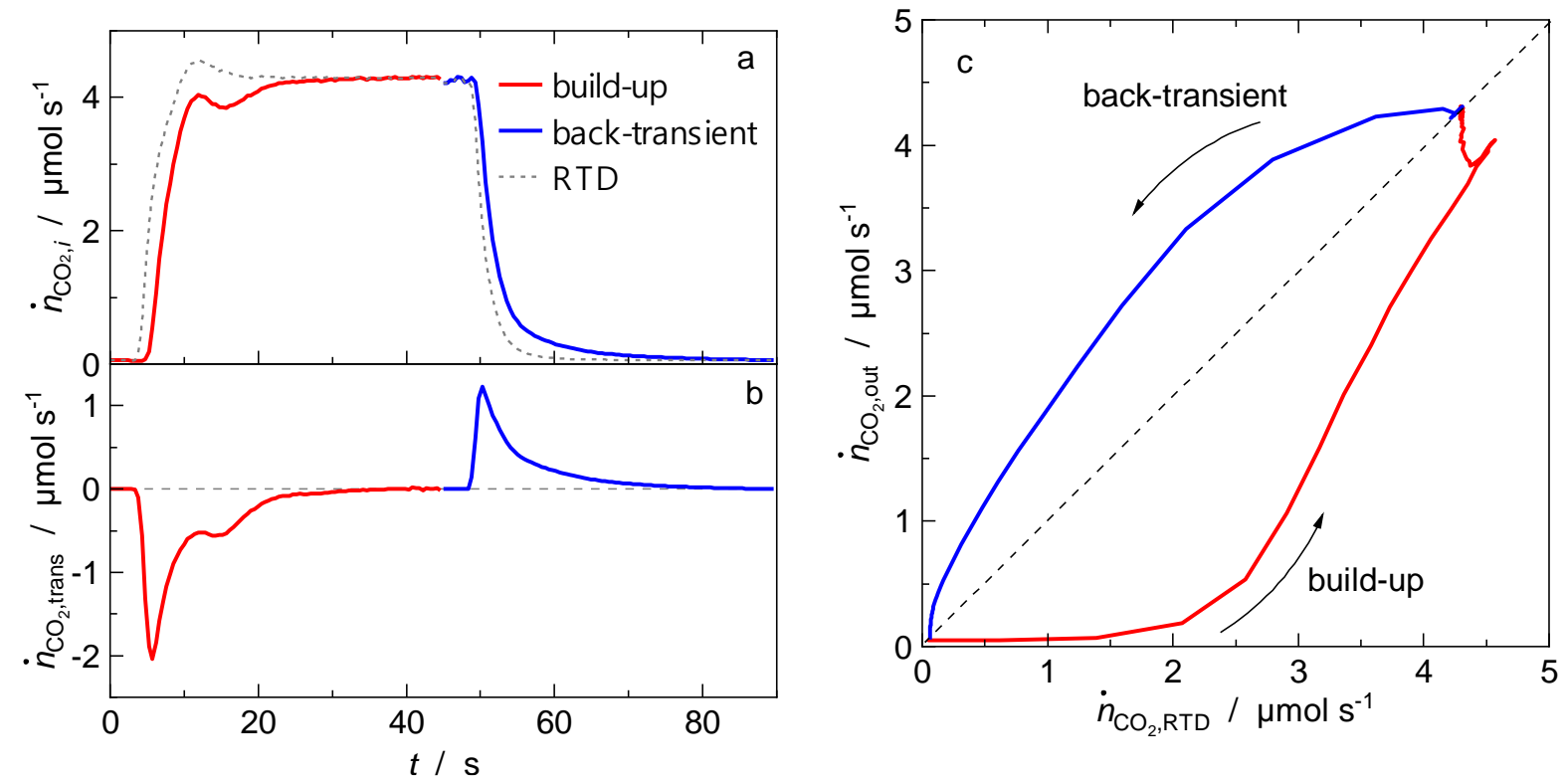

Figure 6: (a) Measured $\dot{n}_{\mathrm{CO}_{2} \text {,out }}$ (red) and theoretical $\dot{n}_{\mathrm{CO}_{2}, \mathrm{RTD}}$ (grey, dashed) response of $\mathrm{CO}_{2}$ during the average LC, (b) corresponding transient molar flow rate of $\mathrm{CO}_{2}$, (c) measured $\mathrm{CO}_{2}$ molar flow rate as function of the theoretical value in the state-space plot; reaction conditions: $313 \mathrm{~K}, 2$ bar, total feed flow rate $250 \mathrm{mLstp} \mathrm{min}^{-1}$, feed gas composition in vol.-\%: $40 \mathrm{H}_{2}, 49 \mathrm{He}, 10 \mathrm{CO}_{2}, 1 \mathrm{Ar}$ (build-up phase), 40 $\mathrm{H}_{2}, 60 \mathrm{He}$ (back-transient phase).

In Figure $6 \mathrm{a}$ a deviation in the build-up phase between the measured and theoretical $\mathrm{CO}_{2}$ response is observed, which causes a negative transient molar flow rate with a maximum of $2 \mu \mathrm{mol} \mathrm{s}^{-1}$. In the state space plot the negative transient molar flow rate during the build-up phase causes a hysteresis below the linear relationship given by the dashed line. Note that a linear relationship would mean that the measured and the theoretical $\mathrm{CO}_{2}$ response is identical, indicating the $\mathrm{CO}_{2}$ signal being affected by RTD only. The negative transient molar flow rate is caused by a sink of $\mathrm{CO}_{2}$, which is thus removed from the gas phase due to adsorption at the surface. Furthermore, the maximum in transient molar flow rate in the early stage of the build-up phase indicates fast adsorption of $\mathrm{CO}_{2}$ at the alumina surface, which is still barely covered by adsorbent. With time the surface coverage increases resulting in the transient molar flow rate approaching zero towards the end of the build-up phase.

During the back-transient phase, in contrast, the transient molar flow rate is positive also exhibiting a maximum in the early stage. Hence, the hysteresis in the state-space plot exhibits a higher value than expected from RTD. This observation indicates that $\mathrm{CO}_{2}$ desorbs from the solid surface into the gas phase, which is more pronounced for high surface coverages early in the back-transient phase.

Further evaluation of the data can be performed by the integration of the transient molar flow rate during the back-transient phase, which yields the molar amount of $\mathrm{CO}_{2}$ 
desorbed. Therefore, the average back-transient phase and the last cycle is distinguished from each other and compared the sorption capacity measured volumetrically at an equal $\mathrm{CO}_{2}$ partial pressure and temperature (Triflex, micromeritics). After the last switch to the $\mathrm{H}_{2} / \mathrm{He}$ feed gas mixture the transient molar flow of $\mathrm{CO}_{2}$ is integrated over $180 \mathrm{~s}$ and sums up to $17 \mu \mathrm{mol}$, which is in reasonable agreement with the adsorption capacity of $24 \mu \mathrm{mol}$ measured volumetrically. The deviation between the adsorbed amount determined by volumetric and flow methods, however, is in accordance with literature, where a lower adsorption capacity of $\mathrm{CO}_{2}$ during pulse experiments compared to volumetric measurements is reported $[18,73]$. The reason is that equilibrium between the gas phase and the adsorbed species is not reached during flow experiments, while volumetric measurements are performed in order to ensure equilibrium conditions to be fulfilled.

However, the amount of $\mathrm{CO}_{2}$ desorbing during the average back-transient phase amounts to $9 \mu \mathrm{mol}$ and is thus significantly below the theoretical value and that of the last cycle. Hence, this difference between the average and the last cycle indicates incomplete desorption of $\mathrm{CO}_{2}$ during the half cycle period of $45 \mathrm{~s}$. Note that $\mathrm{CO}_{2}$ is only weakly adsorbed at the surface, as found by temperature programmed desorption (TPD) experiments up to $400{ }^{\circ} \mathrm{C}$ (see Appendix, Figure S10), confirming the sorption process being completely reversible.

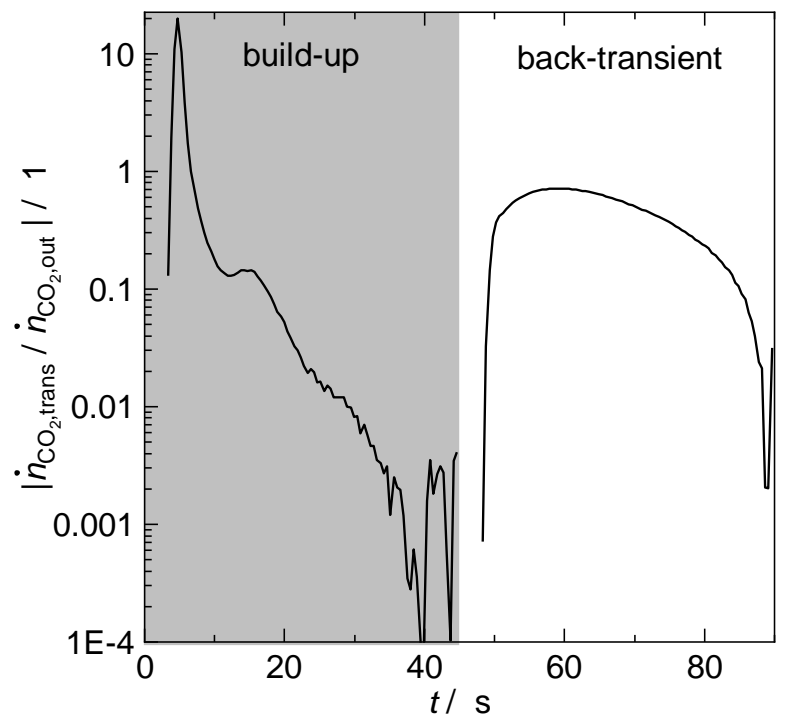

Figure 7: Relative transient molar flow rate for one average limit cycle for the adsorption of $\mathrm{CO}_{2}$ on $\mathrm{Al}_{2} \mathrm{O}_{3}$. Interestingly, the relative transient molar flow rate and thus the signal-to-noise ratio changes within each half-period and also differs for the build-up and back-transient phase. This becomes evident, if one considers that $\dot{n}_{i, \text { out }}$ follows the RTD and thus changes with time on the one hand. On the other hand, $\dot{n}_{i \text {,trans }}$ also changes with time depending on the underlying interaction mechanism with the catalyst. If ad- or desorption at the solid surface occurs, for instance, the surface coverage changes with time and therefore the sorption rate, as well. For illustration, the relative transient molar flow rate for one period is shown in Figure 7 . Note that the time delay of the system amounts to $4 \mathrm{~s}$, for which no meaningful data is available. It can be observed that the relative transient molar flow rate rises rapidly in the build-up phase and reaches a maximum within $10 \mathrm{~s}$. During that phase the transient molar flow rate of $\mathrm{CO}_{2}$ is high, since $\mathrm{CO}_{2}$ 
adsorption is favored given by the low surface coverage. At the same time the system response in terms of $\dot{n}_{\mathrm{CO}_{2} \text {,out }}$ is still at a low level, due to the RTD. Hence, the fast processes at the catalyst surface can be resolved very well in that early stage. In the later stage during the build-up phase, however, transient molar flow rate of $\mathrm{CO}_{2}$ decreases, due to surface saturation, accompanied by a raising value for $\dot{n}_{\mathrm{CO}_{2} \text {,out }}$. Therefore, the relative transient molar flow rate decreases, which corresponds to a decrease in the signal-to-noise ratio. During the back-transient phase, in contrast, the relative transient molar flow rate is less noisy, since $\dot{n}_{\mathrm{CO}_{2} \text {,out }}$ is decreasing with time according to the RTD leading to an increase in the $\dot{n}_{\mathrm{CO}_{2} \text {, trans }} / \dot{n}_{\mathrm{CO}_{2} \text {,out }}$ ratio. In addition to that $\dot{n}_{\mathrm{CO}_{2} \text {,trans }}$ is high in the early stage of the back-transient phase, due to high desorption rates given by the initially high surface coverages and decreases with time, as well. This gives raise to resolve slow processes in the interaction between gaseous species and the solid surface, which occur close to the steady-state. It is recommended to analyze and compare both half-periods in order to minimize the error in determination of the transient molar flow rates.

\subsection{Example II: CO methanation}

For the example of $\mathrm{CO}$ methanation the response in form of the measured outlet molar flow rate $\dot{n}_{i, \text { out }}$ for $\mathrm{CO}$ and $\mathrm{CH}_{4}$ are shown in comparison to the theoretical values $\dot{n}_{i, \mathrm{RTD}}$ in Figure $8 \mathrm{a}$, while the corresponding transient molar flow rates $\dot{n}_{i, \text { trans }}$ are displayed in Figure 8b. Note, that the $\mathrm{CO}$ signal is scaled in order to be displayed together with $\mathrm{CH}_{4}$. The comparison of the results shown in Figure 8 (a vs. b) exhibits that $\mathrm{CO}$ follows the RTD, though a significant transient molar flow rate is calculated. This discrepancy can be explained by the fact that the relative transient molar flow rate $\dot{n}_{\mathrm{CO} \text {,trans }} / \dot{n}_{\mathrm{CO} \text {,out }}$ is small. We therefore focus on Figure $8 \mathrm{~b}$ for further discussion.
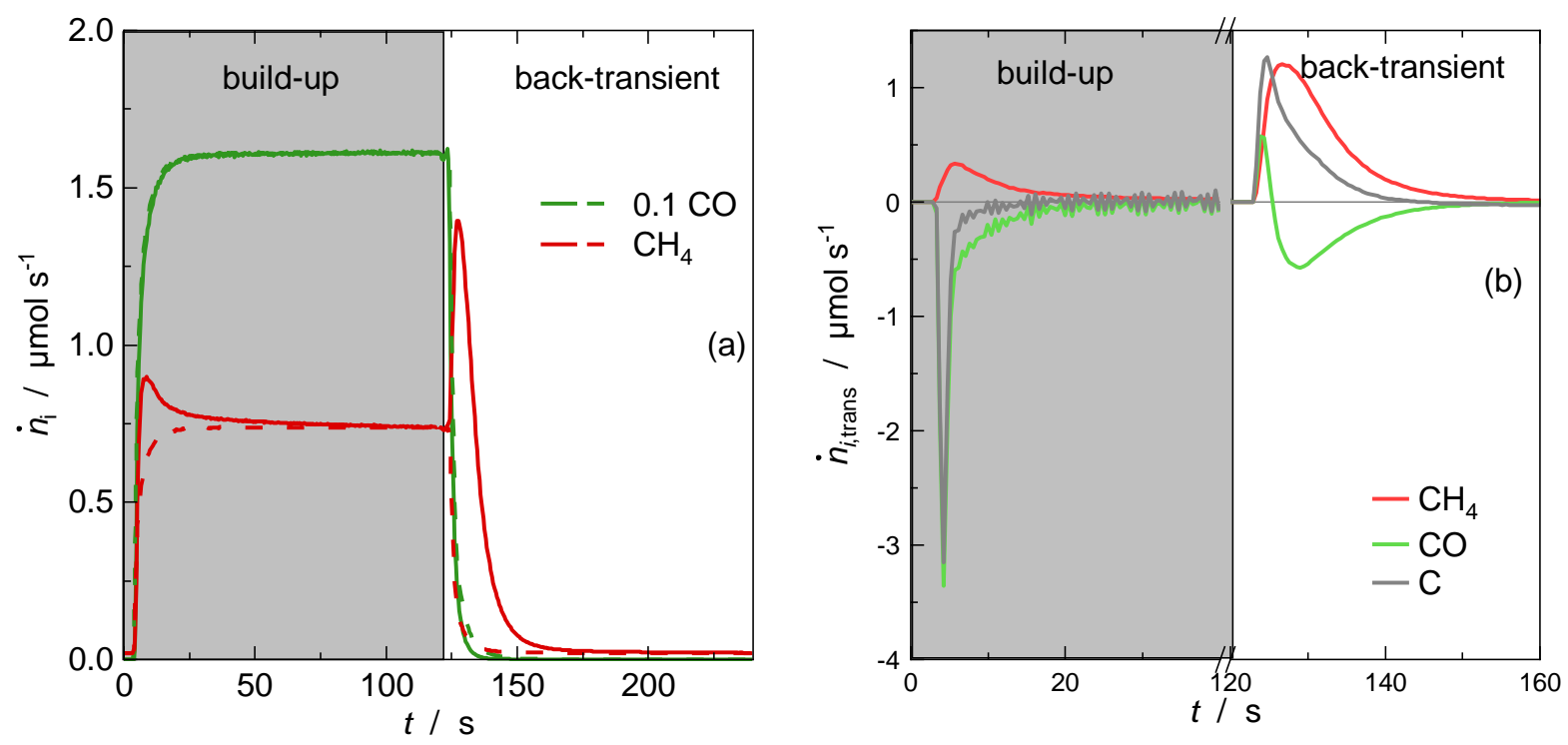

Figure 8: (a) measured outlet molar flow rates $\dot{n}_{i, \text { out }}$ (solid lines) of $\mathrm{CO}$ (green) and $\mathrm{CH}_{4}$ (red) and theoretical values $\dot{n}_{i, \mathrm{RTD}}$ (dashed lines) during one limit cycle; (b) corresponding transient molar flows rates and the transient $C$ balance is shown; reaction conditions: $556 \mathrm{~K}, 2$ bar, total feed flow rate $250 \mathrm{mLsTP}$ min $^{-1}$, feed gas composition in vol.- $\%$ : $40 \mathrm{H}_{2}, 49 \mathrm{He}, 10 \mathrm{CO}, 1 \mathrm{Ar}$ (build-up phase), $40 \mathrm{H}_{2}, 60 \mathrm{He}$ (backtransient phase). 
During the build-up phase (switch from $\mathrm{H}_{2} / \mathrm{He}$ to $\mathrm{CO} / \mathrm{Ar} / \mathrm{H}_{2} / \mathrm{He}$ ) a significant negative transient molar flow rate for $\mathrm{CO}$ is observed shortly after the switching event, which indicates strong $\mathrm{CO}$ adsorption. At the same time a positive transient molar flow rate for $\mathrm{CH}_{4}$ indicates product formation and desorption into the gas phase. The interplay between both species can be evaluated by the transient molar flow rate of carbon species at the surface $\dot{n}_{\mathrm{C} \text {,trans }}$ according to eq. (10). The negative value during the buildup phase indicates that the $\mathrm{CO}$ adsorbed at the surface is not only converted into $\mathrm{CH}_{4}$ but is also stored at the surface, which indicates that $\mathrm{CO}$ adsorption is a rather fast process. This is in accordance to Bundhoo et al., who reported a temporal delay of the formation of $\mathrm{CH}_{4}$ after the adsorption of $\mathrm{CO}$ on a Ni catalyst [22].

During the back-transient phase the transient molar flow rate of $\mathrm{CH}_{4}$ exhibits positive values, while that for $\mathrm{CO}$ and overall carbon is positive at first and turns negative before approaching zero. The positive transient molar flow rate of $\mathrm{CH}_{4}$ is attributed to the hydrogenation of a highly reactive intermediates adsorbed at the surface and subsequent desorption of the $\mathrm{CH}_{4}$ formed, according to literature $[43,58,72,74]$. Those intermediate are assigned as $\mathrm{CH}_{\mathrm{x}}$ species, which are converted into $\mathrm{CH}_{4}$ in the following two-step mechanism proposed by Bundhoo et al. [22]: First, metallic sites at the catalyst surface are released by desorption or reaction of adsorbed species, which enhances the atomic hydrogen supply. In the following step the adsorbed reactive intermediate reacts with the available hydrogen to gaseous $\mathrm{CH}_{4}$.

The positive transient molar flow rate of $\mathrm{CO}$ in the early stage of the back-transient phase indicates $\mathrm{CO}$ desorption from the surface, due to decreasing $\mathrm{CO}$ partial pressure in the gas phase during the back-transient phase. Due to ongoing surface reaction further sorption sites become available with time, which leads to a (re-)adsorption of $\mathrm{CO}$ still available in the gas phase and therefore negative transient molar flow rates of $\mathrm{CO}$. Obviously, this effect requires the surface reaction to be sufficiently fast, in order to release sorption sites, while $\mathrm{CO}$ is still present in the gas phase. The latter is governed by the residence time distribution of the reactor. The $\mathrm{CO}$ adsorbed in that later phase will also be converted into $\mathrm{CH}_{4}$ as long as sufficient $\mathrm{H}_{2}$ is available and thereby contributes to the positive transient molar flow rate of $\mathrm{CH}_{4}$ in that phase, as well. The transient molar flow rate of carbon corresponds to the carbon balance given in eq. (10), which is positive during the back-transient phase. This indicates that deposits of carbonaceous species formed during build-up phase are hydrogenated to $\mathrm{CH}_{4}$ due to the excess in hydrogen during the back-transient phase.

\section{Conclusion}

The PTK methodology is introduced in order to investigate the interplay of transient kinetic processes in heterogeneously catalyzed reactions under realistic conditions (i.e. elevated pressures). It allows to derive the molar flow rates between the gas phase and the catalyst surface quantitatively based on the transient reactor response with respect to gas phase composition and thus complements techniques focusing on analyzing the dynamics at the catalyst surface itself. In the contribution, the experimental procedure and equipment is described together with model-based evaluation of the experimental data. The strength of the PTK method relies on periodic step-shaped 
changes in feed gas composition, which induce a periodic reactor response, as well. Therefore, a limit cycle is reached for reversible interactions between the gas phase and the catalyst surface, which is evaluated statistically in order to provide reliable data for subsequent interpretation. In particular, the dynamic response with respect to the outlet molar flow rates of the reactive species present in the gas phase is evaluated in the limit cycle providing narrow confidence intervals. In order to distinguish the residence time behavior from transient processes related to interaction with the surface an internal standard is monitored and considered in result analysis. This approach provides the basis for evaluation of transient processes based on the material balances, exhibiting minor deviations only, and thus to resolve even small dynamic effects. Therefore, the presented PTK method is capable to link the transient behavior of single components to the dynamic response of the reactor. The evaluation procedure based on material balances of the catalyst surface and the overall reactor further provides the capability to deduce reaction kinetics valid under dynamic operation conditions from respective experimental results.

The methodology is demonstrated for two examples in the context of the methanation reaction. The adsorption of $\mathrm{CO}_{2}$ at $\mathrm{Al}_{2} \mathrm{O}_{3}$ represents a non-reactive reversible process, while for hydrogenation of $\mathrm{CO}$ into $\mathrm{CH}_{4}$ sinks and sources exist for reactants and products, respectively. The results reveal that the dynamics of the ad- and desorption processes can be resolved and quantitatively evaluated in terms of molar flow rates. Such information allows to deduce the kinetics of those processes under reaction conditions, which is very important for modeling and simulation of chemical reactors operated under dynamic conditions. The second example shows that experimental data can be obtained, which provide the basis to even derive the kinetics of sink and source terms under dynamic conditions. Since the PTK method is not limited to both examples reported, it allows to derive kinetic information for various heterogenously catalyzed gasphase reactions operated dynamically under realistic reaction conditions.

\section{Acknowledgments}

The authors want to thank Sasol Germany $\mathrm{GmbH}$ for providing the support material. Sarah Hoffmann is acknowledged for the support during the installation of the experimental setup.

\section{Funding}

This research did not receive any specific grant from funding agencies in the public, commercial, or not-for-profit sectors. 


\section{Appendix}
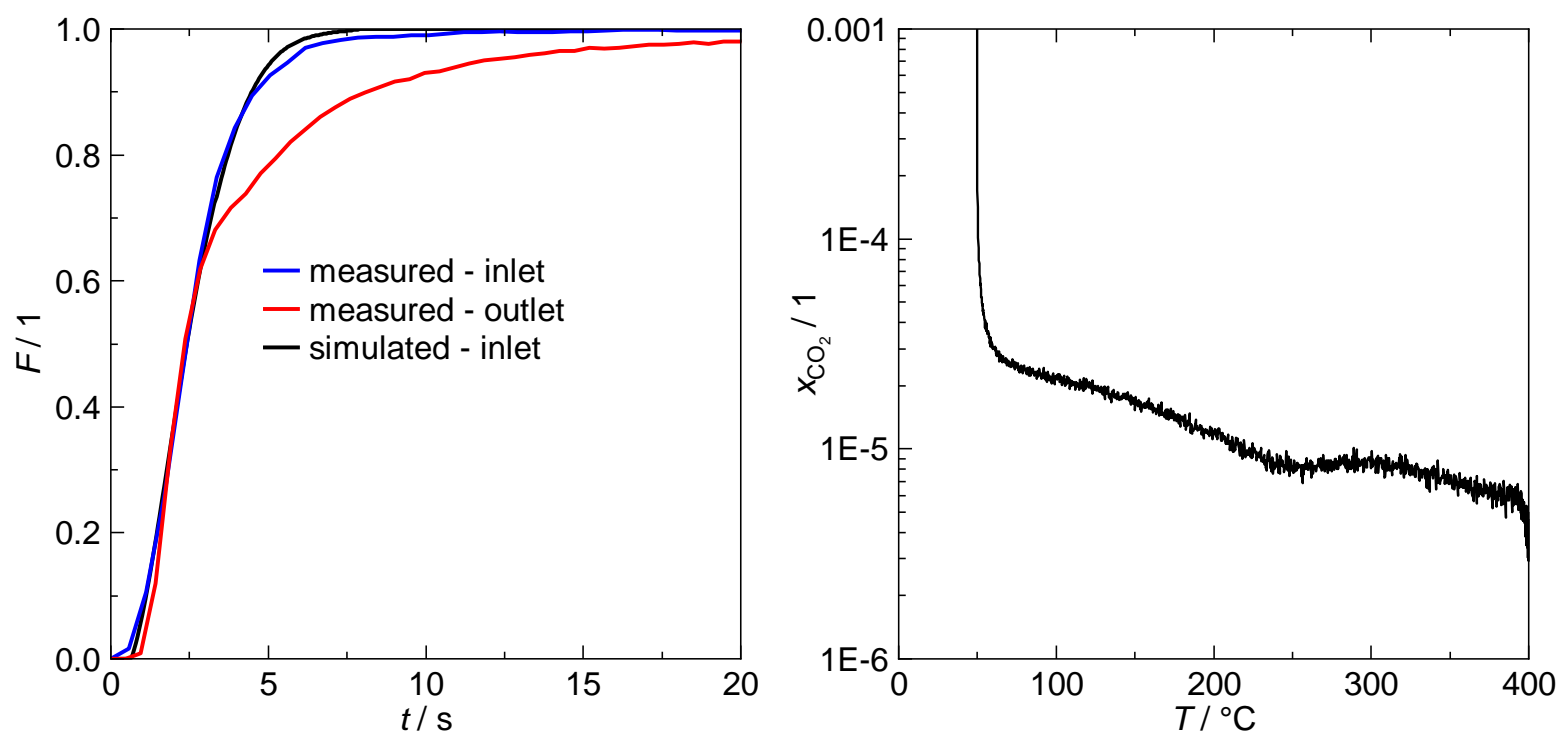

Figure S9: Cumulative function $F$ measured at the Figure S10: $\mathrm{CO}_{2}$ signal during a TPD measureinlet and the outlet of the reactor with catalyst ment directly conducted after adsorption/desorppacking as well as simulated signal at reactor inlet tion experiments at $\mathrm{Al}_{2} \mathrm{O}_{3}$ at $50{ }^{\circ} \mathrm{C}$; the TPD shows assuming laminar flow between switching valve no desorption of $\mathrm{CO}_{2}$ at higher temperatures. and reactor inlet.

\section{List of Symbols}

Symbol

Description

Unit

Latin letters

C

Constant

1

F

Step response

1

$N_{\Theta}$

Evaluated number of periods in limit cycle

1

$n$

Molar amount

mol

$\dot{n}$

Molar flow rate

$\mathrm{mol} \mathrm{s}^{-1}$

$\overline{\dot{n}}$

Average molar flow rate

$\mathrm{mol} \mathrm{s}^{-1}$

$\Delta \overline{\dot{n}}^{2}$

Variance

$\left(\mathrm{mol} \mathrm{s}^{-1}\right)^{2}$

$p$

Operating pressure

bar

$r$

Extensive reaction rate

$\mathrm{mol} \mathrm{s}^{-1}$

$R$

Universal gas constant

$\mathrm{J} \mathrm{mol}^{-1} \mathrm{~K}^{-1}$

$T$

Operating temperature

$\mathrm{K}$

Time

S

$\dot{V}$

Volumetric flow rate

$\mathrm{mLSTP} \min ^{-1}$

$x$

Molar fraction

1

Greek letters

$\alpha$

Volume contraction factor 


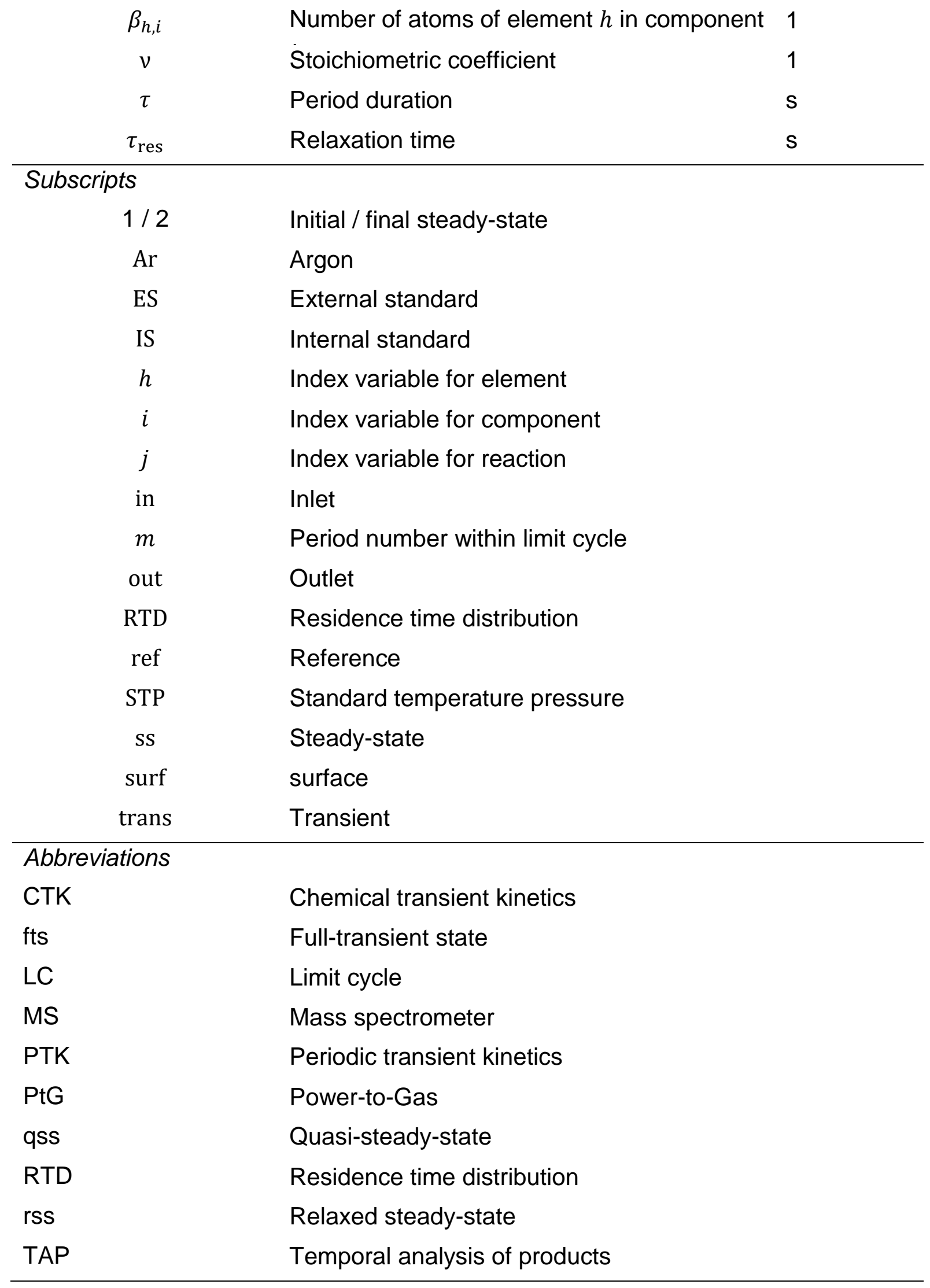




\section{References}

[1] K.F. Kalz, R. Kraehnert, M. Dvoyashkin, R. Dittmeyer, R. Gläser, U. Krewer, K. Reuter, J.-D. Grunwaldt, Future Challenges in Heterogeneous Catalysis: Understanding Catalysts under Dynamic Reaction Conditions, ChemCatChem 9 (2017) 17-29. https://doi.org/10.1002/cctc.201600996.

[2] M. Götz, J. Lefebvre, F. Mörs, A. McDaniel Koch, F. Graf, S. Bajohr, R. Reimert, T. Kolb, Renewable Power-to-Gas: A technological and economic review, Renew. Energy 85 (2016) 1371-1390. https://doi.org/10.1016/j.renene.2015.07.066.

[3] S. Rönsch, J. Schneider, S. Matthischke, M. Schlueter, M. Götz, J. Lefebvre, P. Prabhakaran, S. Bajohr, Review on methanation - From fundamentals to current projects, Fuel 166 (2016) 276-296. https://doi.org/10.1016/j.fuel.2015.10.111.

[4] K.L. Fischer, H. Freund, On the optimal design of load flexible fixed bed reactors: Integration of dynamics into the design problem, Chem. Eng. J. 393 (2020) 124722. https://doi.org/10.1016/j.cej.2020.124722.

[5] M. Neubert, J. Widzgowski, S. Rönsch, P. Treiber, M. Dillig, J. Karl, SimulationBased Evaluation of a Two-Stage Small-Scale Methanation Unit for Decentralized Applications, Energy Fuels 31 (2017) 2076-2086.

https://doi.org/10.1021/acs.energyfuels.6b02793.

[6] J.A. Moulijn, J. Perez-Ramirez, A. van Diepen, M.T. Kreutzer, F. Kapteijn, Catalysis Engineering on Three Levels, Int. J. Chem. React. Eng. 1 (2003) 1-17. https://doi.org/10.2202/1542-6580.1093.

[7] H. Freund, R. Güttel, R. Horn, U. Krewer, J. Sauer, Technische Chemie, Nachr. Chem. 68 (2020) 46-53. https://doi.org/10.1002/nadc.20204097163.

[8] C.O. Bennett, The transient method and elementary steps in heterogeneous catalysis, Cat. Rev. 13 (1976) 121-148.

https://doi.org/10.1080/00087647608069936.

[9] P. Biloen, Incorporation of surface carbon into hydrocarbons during FischerTropsch synthesis: Mechanistic implications, J. Catal. 58 (1979) 95-107. https://doi.org/10.1016/0021-9517(79)90248-3.

[10] J. Happel, Transient tracing, Chem. Eng. Sci. 33 (1978) 1567. https://doi.org/10.1016/0009-2509(78)85214-2.

[11] S.L. Shannon, J.G. Goodwin, Characterization of Catalytic Surfaces by IsotopicTransient Kinetics during Steady-State Reaction, Chem. Rev. 95 (1995) 677695. https://doi.org/10.1021/cr00035a011.

[12] A. Raub, H. Karroum, M. Athariboroujeny, N. Kruse, Chemical Transient Kinetics in Studies of the Fischer-Tropsch Reaction and Beyond, Catal. Lett. 151 (2021) 613-626. https://doi.org/10.1007/s10562-020-03294-w.

[13] C. Ledesma, J. Yang, D. Chen, A. Holmen, Recent Approaches in Mechanistic and Kinetic Studies of Catalytic Reactions Using SSITKA Technique, ACS Catal. 4 (2014) 4527-4547. https://doi.org/10.1021/cs501264f.

[14] J.T. Gleaves, J.R. Ebner, T.C. Kuechler, Temporal Analysis of Products (TAP)A Unique Catalyst Evaluation System with Submillisecond Time Resolution, Cat. Rev. 30 (1988) 49-116. https://doi.org/10.1080/01614948808078616. 
[15] J.T. Gleaves, G.S. Yablonskii, P. Phanawadee, Y. Schuurman, TAP-2: An interrogative kinetics approach, Appl. Catal., A 160 (1997) 55-88.

https://doi.org/10.1016/S0926-860X(97)00124-5.

[16] S.O. Shekhtman, G.S. Yablonsky, S. Chen, J.T. Gleaves, Thin-zone TAP-reactor - theory and application, Chem. Eng. Sci. 54 (1999) 4371-4378. https://doi.org/10.1016/S0009-2509(98)00534-X.

[17] T. Mori, H. Masuda, H. Imai, A. Miyamoto, S. Baba, Y. Murakami, Kinetics, isotope effects, and mechanism for the hydrogenation of carbon monoxide on supported nickel catalysts, J. Phys. Chem. 86 (1982) 2753-2760.

[18] J. Friedland, B. Kreitz, H. Grimm, T. Turek, R. Güttel, Measuring Adsorption Capacity of Supported Catalysts with a Novel Quasi-Continuous Pulse Chemisorption Method, ChemCatChem (2020) 4373-4386. https://doi.org/10.1002/cctc.202000278.

[19] J. Friedland, T. Turek, R. Güttel, Investigations on the Low Temperature Methanation with Pulse Reaction of CO, Chem. Ing. Tech. 88 (2016) 1833-1838. https://doi.org/10.1002/cite.201600056.

[20] A. Frennet, C. Hubert, Transient kinetics in heterogeneous catalysis by metals, J. Mol. Catal. A: Chem. 163 (2000) 163-188. https://doi.org/10.1016/S13811169(00)00385-X.

[21] E. Vesselli, J. Schweicher, A. Bundhoo, A. Frennet, N. Kruse, Catalytic $\mathrm{CO}_{2} \mathrm{Hy}-$ drogenation on Nickel: Novel Insight by Chemical Transient Kinetics, J. Phys. Chem. C 115 (2011) 1255-1260. https://doi.org/10.1021/jp106551r.

[22] A. Bundhoo, J. Schweicher, A. Frennet, N. Kruse, Chemical Transient Kinetics Applied to CO Hydrogenation over a Pure Nickel Catalyst, J. Phys. Chem. C 113 (2009) 10731-10739. https://doi.org/10.1021/jp902647z.

[23] W.T. Ralston, G. Melaet, T. Saephan, G.A. Somorjai, Evidence of Structure Sensitivity in the Fischer-Tropsch Reaction on Model Cobalt Nanoparticles by TimeResolved Chemical Transient Kinetics, Angew. Chem. Int. Ed. 56 (2017) 74157419. https://doi.org/10.1002/anie.201701186.

[24] J. Schweicher, A. Bundhoo, N. Kruse, Hydrocarbon chain lengthening in catalytic $\mathrm{CO}$ hydrogenation: evidence for a $\mathrm{CO}$-insertion mechanism, J. Am. Chem. Soc. 134 (2012) 16135-16138. https://doi.org/10.1021/ja3068484.

[25] M. Athariboroujeny, A. Raub, V. lablokov, S. Chenakin, L. Kovarik, N. Kruse, Competing Mechanisms in CO Hydrogenation over Co-MnOx Catalysts, ACS Catal. 9 (2019) 5603-5612. https://doi.org/10.1021/acscatal.9b00967.

[26] W. Chen, R. Pestman, B. Zijlstra, I.A.W. Filot, E.J.M. Hensen, Mechanism of Cobalt-Catalyzed CO Hydrogenation: 1. Methanation, ACS Catal. 7 (2017) 80508060. https://doi.org/10.1021/acscatal.7b02757.

[27] W. Chen, I.A.W. Filot, R. Pestman, E.J.M. Hensen, Mechanism of Cobalt-Catalyzed CO Hydrogenation: 2. Fischer-Tropsch Synthesis, ACS Catal. 7 (2017) 8061-8071. https://doi.org/10.1021/acscatal.7b02758.

[28] Y.S. Matros, Forced unsteady-state processes in heterogeneous catalytic reactors, Can. J. Chem. Eng. 74 (1996) 566-579.

https://doi.org/10.1002/cjce.5450740504. 
[29] A. Stankiewicz, M. Kuczynski, An industrial view on the dynamic operation of chemical converters, Chem. Eng. Process. 34 (1995) 367-377.

https://doi.org/10.1016/0255-2701(95)00537-4.

[30] P.L. Silveston, R.R. Hudgins, A.A. Adesina, G.S. Ross, J.L. Feimer, Activity and selectivity control through periodic composition forcing over Fischer-Tropsch catalysts, Chem. Eng. Sci. 41 (1986) 923-928. https://doi.org/10.1016/00092509(86)87176-7.

[31] R.J. Berger, F. Kapteijn, J.A. Moulijn, G.B. Marin, J. de Wilde, M. Olea, D. Chen, A. Holmen, L. Lietti, E. Tronconi, Y. Schuurman, Dynamic methods for catalytic kinetics, Appl. Catal., A 342 (2008) 3-28. https://doi.org/10.1016/j.apcata.2008.03.020.

[32] P.L. Silveston, R.R. Hudgins (Eds.), Periodic operation of reactors, 1st ed., Elsevier, Amsterdam, Boston, Kidlington, Oxford, U.K, Waltham, Mass, 2013.

[33] F.J.M. Horn, R.C. Lin, Periodic processes: a variational approach, Ind. Eng. Chem. Proc. Des. Dev. 6 (1967) 21-30. https://doi.org/10.1021/i260021a005.

[34] R.R. Hudgins, P.L. Silveston, A. Renken, Y.S. Matros, Introduction, in: P.L. Silveston, R.R. Hudgins (Eds.), Periodic operation of reactors, firstst, Elsevier, Amsterdam, Boston, Kidlington, Oxford, U.K, Waltham, Mass, 2013, pp. 1-22.

[35] J.E. Bailey, F.J.M. Horn, R.C. Lin, Cyclic operation of reaction systems: Effects of heat and mass transfer resistance, AIChE J. 17 (1971) 818-825. https://doi.org/10.1002/aic.690170410.

[36] D. Meyer, J. Friedland, T. Kohn, R. Güttel, Transfer Functions for Periodic Reactor Operation: Fundamental Methodology for Simple Reaction Networks, Chem. Eng. Technol. 40 (2017) 2096-2103. https://doi.org/10.1002/ceat.201700122.

[37] L.M. Aparicio, Transient Isotopic Studies and Microkinetic Modeling of Methane Reforming over Nickel Catalysts, J. Catal. 165 (1997) 262-274. https://doi.org/10.1006/jcat.1997.1468.

[38] R. Try, A. Bengaouer, P. Baurens, C. Jallut, Dynamic modeling and simulations of the behavior of a fixed-bed reactor-exchanger used for $\mathrm{CO}_{2}$ methanation, AlChE J. 38 (2017) 2039. https://doi.org/10.1002/aic.15874.

[39] R. Yadav, R.G. Rinker, Step-response kinetics of methanation over a nickel/alumina catalyst, Ind. Eng. Chem. Res. 31 (1992) 502-508. https://doi.org/10.1021/ie00002a009.

[40] S.-I. Fujita, H. Terunuma, M. Nakamura, N. Takezawa, Mechanisms of methanation of carbon monoxide and carbon dioxide over nickel, Ind. Eng. Chem. Res. 30 (1991) 1146-1151. https://doi.org/10.1021/ie00054a012.

[41] S.-I. Fujita, M. Nakamura, T. Doi, N. Takezawa, Mechanisms of methanation of carbon dioxide and carbon monoxide over nickel/alumina catalysts, Appl. Catal., A 104 (1993) 87-100. https://doi.org/10.1016/0926-860X(93)80212-9.

[42] J.H. Siddall, M.L. Miller, W.N. Delgass, Transient Kinetic Analysis Of Methane Synthesis Over Unsupported $\mathrm{Co}$ and $\mathrm{Rh} / \mathrm{SiO}_{2}$, Chem. Eng. Commun. 83 (1989) 261-276. https://doi.org/10.1080/00986448908940665.

[43] R.P. Underwood, C.O. Bennett, The $\mathrm{COH}_{2}$ reaction over nickel-alumina studied by the transient method, J. Catal. 86 (1984) 245-253. https://doi.org/10.1016/0021-9517(84)90370-1. 
[44] S. Van Ho, The kinetics of methanation on nickel catalysts, J. Catal. 64 (1980) 272-283. https://doi.org/10.1016/0021-9517(80)90502-3.

[45] A. Frennet, T. Visart de Bocarmé, J.-M. Bastin, N. Kruse, Mechanism and kinetics of the catalytic $\mathrm{CO}-\mathrm{H}_{2}$ reaction: An approach by chemical transients and surface relaxation spectroscopy, J. Phys. Chem. B 109 (2005) 2350-2359. https://doi.org/10.1021/jp048834h.

[46] N. Kruse, J. Schweicher, A. Bundhoo, A. Frennet, T.V. de Bocarmé, Catalytic CO hydrogenation: Mechanism and kinetics from chemical transients at low and atmospheric pressures, Top. Catal. 48 (2008) 145-152.

[47] K. Klusáček, V. Stuchlý, Increasing of carbon monoxide methanation rate by forced feed composition cycling, Catal. Today 25 (1995) 169-174. https://doi.org/10.1016/0920-5861(95)00106-P.

[48] B. Mutz, A. Gänzler, M. Nachtegaal, O. Müller, R. Frahm, W. Kleist, J.-D. Grunwaldt, Surface Oxidation of Supported Ni Particles and Its Impact on the Catalytic Performance during Dynamically Operated Methanation of $\mathrm{CO}_{2}$, Catalysts 7 (2017) 279. https://doi.org/10.3390/catal7090279.

[49] A.A. Adesina, R.R. Hudgins, P.L. Silveston, Fischer-Tropsch synthesis under periodic operation, Catal. Today 25 (1995) 127-144. https://doi.org/10.1016/09205861(95)00103-M.

[50] B. Mutz, H.W.P. Carvalho, W. Kleist, J.-D. Grunwaldt, Dynamic transformation of small Ni particles during methanation of $\mathrm{CO}_{2}$ under fluctuating reaction conditions monitored by operando X-ray absorption spectroscopy, J. Phys. Conf. Ser. 712 (2016) 12050. https://doi.org/10.1088/1742-6596/712/1/012050.

[51] R. Güttel, Study of Unsteady-State Operation of Methanation by Modeling and Simulation, Chem. Eng. Technol. 36 (2013) 1675-1682. https://doi.org/10.1002/ceat.201300223.

[52] M. Marwood, R. Doepper, A. Renken, Modeling of surface intermediates under forced periodic conditions applied to $\mathrm{CO}_{2}$ methanation, Can. J. Chem. Eng. 74 (1996) 660-663. https://doi.org/10.1002/cjce.5450740516.

[53] M. Marwood, F. van Vyve, R. Doepper, A. Renken, Periodic operation applied to the kinetic study of $\mathrm{CO}_{2}$ methanation, Catal. Today 20 (1994) 437-448. https://doi.org/10.1016/0920-5861(94)80137-1.

[54] B. Kreitz, J. Friedland, R. Güttel, G.D. Wehinger, T. Turek, Dynamic Methanation of $\mathrm{CO}_{2}-$ Effect of Concentration Forcing, Chem. Ing. Tech. 91 (2019) 576-582. https://doi.org/10.1002/cite.201800191.

[55] B. Kreitz, G.D. Wehinger, T. Turek, Dynamic simulation of the $\mathrm{CO}_{2}$ methanation in a micro-structured fixed-bed reactor, Chem. Eng. Sci. 195 (2019) 541-552. https://doi.org/10.1016/j.ces.2018.09.053.

[56] N. Nikačević, B. Todić, M. Mandić, M. Petkovska, D.B. Bukur, Optimization of forced periodic operations in milli-scale fixed bed reactor for Fischer-Tropsch synthesis, Catal. Today 343 (2020) 156-164. https://doi.org/10.1016/j.cattod.2018.12.032.

[57] R. Yadav, R.G. Rinker, An experimental study of methane synthesis by concentration forcing, Chem. Eng. Sci. 45 (1990) 3221-3226.

https://doi.org/10.1016/0009-2509(90)80214-Y. 
[58] A.M. Efstathiou, C.O. Bennett, Surface species on $\mathrm{Rh} / \mathrm{Al}_{2} \mathrm{O}_{3}$ during $\mathrm{CO} / \mathrm{H}_{2}$ reaction studied by transient techniques, Chem. Eng. Commun. 83 (1989) 129-146. https://doi.org/10.1080/00986448908940658.

[59] K. Schädlich, U. Hoffmann, H. Hofmann, Periodical operation of chemical processes and evaluation of conversion improvements, Chem. Eng. Sci. 38 (1983) 1375-1384. https://doi.org/10.1016/0009-2509(83)80073-6.

[60] J.E. Bailey, Periodic Operation of Chemical Reactors: A Review, Chem. Eng. Commun. 1 (1974) 111-124. https://doi.org/10.1080/00986447408960421.

[61] A. Marković, A. Seidel-Morgenstern, M. Petkovska, Evaluation of the potential of periodically operated reactors based on the second order frequency response function, Chem. Eng. Res. Des. 86 (2008) 682-691. https://doi.org/10.1016/j.cherd.2008.02.003.

[62] J.M. Douglas, Periodic Reactor Operation, Ind. Eng. Chem. Process Des. Dev. 6 (1967) 43-48. https://doi.org/10.1021/i260021a008.

[63] A. Renken, Verbesserung von Selektivität und Ausbeute durch periodische Prozeßührung, Chem. Ing. Tech. 46 (1974) 113.

[64] R. Currie, D. Nikolić, M. Petkovska, D.S.A. Simakov, $\mathrm{CO}_{2}$ Conversion Enhancement in a Periodically Operated Sabatier Reactor: Nonlinear Frequency Response Analysis and Simulation-based Study, Isr. J. Chem. 58 (2018) 762-775. https://doi.org/10.1002/ijch.201700134.

[65] D. Nikolić, A. Seidel-Morgenstern, M. Petkovska, Nonlinear frequency response analysis of forced periodic operation of non-isothermal CSTR using single input modulations. Part I: Modulation of inlet concentration or flow-rate, Chem. Eng. Sci. 117 (2014) 71-84. https://doi.org/10.1016/j.ces.2014.06.013.

[66] P. Biloen, J.N. Helle, F.G.A. van den Berg, W.M.H. Sachtler, On the activity of Fischer-Tropsch and methanation catalysts: A study utilizing isotopic transients, J. Catal. 81 (1983) 450-463. https://doi.org/10.1016/0021-9517(83)90183-5.

[67] C.-H. Yang, Y. Soong, P. Biloen, A comparison of nickel-and platinum-catalyzed methanation, utilizing transient-kinetic methods, J. Catal. 94 (1985) 306-309.

[68] D. Meyer, J. Schumacher, J. Friedland, R. Güttel, Hydrogenation of $\mathrm{CO} / \mathrm{CO}_{2}$ Mixtures on Nickel Catalysts: Kinetics and Flexibility for Nickel Catalysts, Ind. Eng. Chem. Res. 59 (2020) 14668-14678. https://doi.org/10.1021/acs.iecr.0c02072.

[69] J. Gao, Y. Wang, Y. Ping, D. Hu, G. Xu, F. Gu, F. Su, A thermodynamic analysis of methanation reactions of carbon oxides for the production of synthetic natural gas, RSC Adv. 2 (2012) 2358-2368. https://doi.org/10.1039/c2ra00632d.

[70] S.O. Shekhtman, G.S. Yablonsky, Thin-Zone TAP Reactor versus Differential PFR: Analysis of Concentration Nonuniformity for Gas-Solid Systems, Ind. Eng. Chem. Res. 44 (2005) 6518-6522. https://doi.org/10.1021/ie050554g.

[71] C. Mirodatos, Deactivation of nickel-based catalysts during CO methanation and disproportionation, J. Catal. 107 (1987) 275-287. https://doi.org/10.1016/00219517(87)90294-6.

[72] R.E. Hayes, W.J. Thomas, K.E. Hayes, A study of the nickel-catalyzed methanation reaction, J. Catal. 92 (1985) 312-326. https://doi.org/10.1016/00219517(85)90266-0. 
[73] S. Ewald, O. Hinrichsen, On the interaction of $\mathrm{CO}_{2}$ with Ni-Al catalysts, Appl. Catal., A 580 (2019) 71-80. https://doi.org/10.1016/j.apcata.2019.04.005.

[74] D. Stockwell, An isotopic study of chain growth during the $\mathrm{CO} / \mathrm{H}_{2}$ reaction over Ni/Al2O3, J. Catal. 110 (1988) 354-363. https://doi.org/10.1016/00219517(88)90326-0. 